\title{
RIME LENGTH, STRESS, AND ASSOCIATION DOMAINS*
}

\begin{abstract}
Every regular Chinese syllable has a syllable tone (the tone we get when the syllable is read in isolation). In some Chinese languages, the tonal pattern of a multisyllabic expression is basically a concatenation of the syllable tones. In other Chinese languages, the tonal pattern of a multisyllabic expression is determined solely by the initial syllable. I call the former M-languages (represented by Mandarin) and the latter S-languages (represented by Shanghai). I argue that there is an additional difference in rime structures between the two language groups. In S-languages, all rimes are simple, i.e., there are no underlying diphthongs or codas. In M-languages, all regular rimes are heavy. I further argue that a syllable keeps its underlying tones only if it has stress. Independent metrical evidence tells us that heavy rimes may carry inherent stress. Thus, in M-languages, all regular syllables are stressed and retain their underlying tones (which may or may not undergo further changes). In contrast, in S-languages, regular rimes do not carry inherent stress; instead, only those syllables that are assigned stress by rule can keep their underlying tones and hence head a multisyllabic tonal domain.

The present analysis has theoretical implications for the analysis of contour tones, the tone bearing unit, and the interplay between stress and tone.
\end{abstract}

\section{INTRODUCTION}

In this paper I offer a view of tone sandhi according to which the sandhi pattern of a Chinese language (or 'dialect') is related to its syllabic structure and stress (which, as metrical prominence, need not always be realized as greater intensity or duration). To begin the discussion, consider the contrast between Mandarin in (1) and New Shanghai in (2). ${ }^{1}$

$\begin{array}{rlll}\text { (1) a. } & \mathrm{si}^{51}+\mathrm{bei}^{55} & \rightarrow 5155 & \text { 'four cups' } \\ \text { b. } & \mathrm{si}^{51}+\mathrm{pan}^{35} & \rightarrow 5135 & \text { 'four plates' } \\ \text { c. } & \mathrm{si}^{51}+\mathrm{wan}^{214} & \rightarrow 51214 & \text { 'four bowls' } \\ \text { d. } & \mathrm{si}^{51}+\mathrm{pian}^{51} & \rightarrow 5151 & \text { 'four slices' } \\ \text { (2) a. } & \mathrm{sz}^{34}+\mathrm{pe}^{53} & \rightarrow 3344 & \text { 'four cups' } \\ \text { b. } \quad \mathrm{sz}^{34}+\mathrm{wø}^{34} & \rightarrow 3344 & \text { 'four bowls' } \\ \text { c. } \mathrm{sz}^{34}+\mathrm{bø}^{23} & \rightarrow 3344 & \text { 'four plates' } \\ \text { d. } \mathrm{sz}^{34}+\mathrm{kor}^{55} & \rightarrow 3344 & \text { 'four dimes' } \\ \text { e. } & \mathrm{sz}^{34}+\mathrm{ha} \mathrm{p}^{23} & \rightarrow 3344 & \text { 'four boxes' }\end{array}$


In (1) the output tone pattern of the phrase ${ }^{2}$ is the concatenation of the input syllable tones. ${ }^{3}$ In (2), however, the output phrasal tone is determined solely by the initial syllable; input tones on non-initial syllables play no role. The same contrast is seen in longer phrases
(3) a. $\operatorname{shi}^{35}+\mathrm{si}^{51}+$ bei $^{55}$
$\rightarrow 355155$
'fourteen cups'
b. $\operatorname{shi}^{35}+\mathrm{si}^{51}+\operatorname{pan}^{35}$
$\rightarrow 355135$ 'fourteen plates'
c. $\operatorname{shi}^{35}+\operatorname{san}^{55}+\operatorname{wan}^{214}$
$\rightarrow 3555214$ 'thirteen bowls'
d. $\operatorname{shi}^{35}+\operatorname{san}^{55}+\operatorname{pian}^{51}$
$\rightarrow 355551$ 'thirteen slices'
(4) a. $\mathrm{zar}^{23}+\mathrm{sz}^{34}+\mathrm{pe}^{53}$
$\rightarrow 225521$
'fourteen cups'
b. $2 z^{23}+\mathrm{sz}^{34}+\mathrm{wg}^{34}$
$\rightarrow 225521$
'fourteen bowls'
c. $z \partial^{23}+\mathrm{se}^{53}+\mathrm{b} \boldsymbol{\theta}^{23}$
$\rightarrow \quad 225521$
'thirteen plates'
d. $z \partial^{23}+s^{53}+h a^{23}$
$\rightarrow \quad 225521$
'thirteen boxes'

Again, in deriving the output in Mandarin (3), every syllable counts, whereas in deriving the output in New Shanghai (4), only the initial syllable counts.

Several Chinese languages, mostly in the Wu family, such as Danyang, Suzhou, and Wuxi, pattern with New Shanghai, in that the phrasal tone is determined by the initial syllable alone. Most other Chinese languages, such as Tianjin, Cantonese, and Xiamen (Taiwanese), pattern with Mandarin, in that every syllable contributes to the phrasal tone. Let us call the former group S-languages, and the latter M-languages. It is not the case that M-languages do not have tone sandhi; for example, Mandarin, Tianjin, and Xiamen all have quite complicated tone sandhis. However, there is a fundamental difference between tone sandhi in S-languages and that in M-languages. In S-languages, the tonal pattern of a domain is determined by the initial syllable alone, whereas in M-languages all full syllables contribute to the phrasal tone. ${ }^{4}$ For example, Mandarin has a sandhi [214 214] $\rightarrow$ [35214]; the output is determined neither by the first syllable alone, nor by the second alone, but by both. The same is true for the Tianjin sandhi rules: [21 21] $\rightarrow$ [213 21], [213213] $\rightarrow$ [45 213], [53 53] $\rightarrow$ [21 53], and [5321] $\rightarrow$ [45 21] (Li and Liu (1985)). In addition, in Xiamen (and other Min languages), each full syllable has a final tone and a nonfinal tone, yet both tones are the intrinsic properties of a given syllable, and neither tone is predictable from the tone of any other syllable (e.g., Chen (1987)). Thus, the phrasal sandhi in Xiamen is qualitatively different from that in Shanghai. Let us summarize this difference between S-languages and M-languages below. 
(5) a. In M-languages, the underlying tones of all full syllables contribute to the output phrasal tone.

b. In S-languages, only the underlying tone of the initial syllable contributes to the output phrasal tone.

It is not the case that all Wu languages pattern with New Shanghai. For example, in Wenzhou (Zheng-Zhang $(1964,1980)$ ) and Chongming (Zhang (1979)), both being Wu languages, the phrasal tone cannot be deduced from the initial syllable alone. Therefore, the contrast between (1) and (2) is not simply a distinction between $\mathrm{Wu}$ and non-Wu languages.

Tonal patterns like (2) and (4) are characteristic of African tone languages. For example, in Mende, non-initial morphemes in a compound lose their underlying tones, and it is the initial morpheme that determines the pitch pattern of the entire expression (Leben (1973)). In addition, contour tones are analyzable as clusters of level tones (e.g., rise $=\mathrm{LH}$, fall $=\mathrm{HL}$, rise-fall $=\mathrm{LHL}$, etc.), tones are generally linked to syllables one-to-one according to the Association Conventions, and contour tones mostly occur in domain final positions only (cf. Williams (1971/6), Goldsmith (1976), Pulleyblank (1986), among many others; cf. Selkirk and Shen (1990) for a level tone analysis of New Shanghai). On the other hand, tonal patterns like (1) and (3) go against the Association Conventions, since contour tones freely occur anywhere and do not seem to be analyzable as level tones. Yip $(1989,1992)$, Bao $(1990,1992)$ and Chen (1992), among others, account for (1) and (3) by proposing that Chinese tones have a different structure from African tones. However, there remains a typological puzzle: why does New Shanghai (and a few other dialects) behave like African languages and unlike other Chinese languages?

In the following sections I will sketch a theory that provides an explanation for (5) and for the typological puzzle. I will argue that (5) follows from a set of independent principles. In particular, I will suggest that there is a connection between rime length, stress, and tonal association domain (to be explained in Section 3.3). In M-languages, the rime has two X slots (bimoraic) and so is heavy, whereas in S-languages, the rime has one $\mathrm{X}$ slot (monomoraic) and so is light. It is well-known in metrical phonology that heavy syllables may bear inherent stress (Hayes (1980), Halle and Vergnaud (1987), Prince (1992)), while light syllables get stress only by rule. In addition, in Chinese languages stressless syllables may lose their underlying tones, just as stressless vowels may lose voicing in Southern Paiute (Halle and Clements (1985)) and Chatino (Kenstowicz and Kisseberth (1979), citing Gleason (1955)), or lose height and backness to 
become schwa in English. Consequently, in M-languages, all full syllables are stressed and retain their underlying tones, all of which contribute (directly or via dissimilation, etc.) to the output phrasal tone. In contrast, in S-languages, only the initial syllable, which is assigned stress by rule (cf. Section 3), retains its underlying tones and solely determines the phrasal tone.

This paper is organized as follows. In Section 2, I discuss the difference in rime length between M-languages and S-languages. In Section 3, I discuss stress and its relation to rime length and association domains. In Section 4, I analyze tone sandhi in M-languages and S-languages. In Section 5, I offer a historical perspective of languages whose sandhi patterns lie between M-languages and S-languages. In Section 6, I make a few concluding remarks.

\section{RIME LENGTH}

\subsection{Rime}

I use 'rime length' to refer to the number of $\mathrm{X}$ slots in the rime (cf. Levin (1985), Sagey (1986)). I discuss rime length, instead of syllable length, for the reason that onset consonants do not contribute to 'syllabic weight', i.e., the ability to bear stress and tone (cf. Hayes (1980), Halle and Vergnaud (1980), Hyman (1985), among others). ${ }^{5}$ In addition, I will not distinguish the $\mathrm{X}$ slot theory from the moraic theory, but assume that each $\mathrm{X}$ slot in the rime is equivalent to one mora. Thus, the Mandarin words man 'full' and the Cantonese word hok 'shell' both have two rime slots and are both bimoraic.

All Chinese languages allow a glide between the onset consonant and the nuclear vowel. Traditionally, the prenuclear glide is often transcribed as part of the 'final' (loosely equivalent to 'rime'), instead of part of the onset. The main reason for this analysis is the desire to reduce the number of phonemic symbols (Chao (1934/1957), Li (1983)). There is, however, no evidence that this glide adds any weight to the rime. For example, in his acoustic study of Mandarin, Howie (1976) shows that in GV and GVX syllables, the initial glide behaves like other sonorant onsets and adds about $100 \mathrm{~ms}$ in duration. On the other hand, CVX and CGVX have similar durations, i.e., the medial $\mathrm{G}$ does not increase the syllable duration. This suggests that the medial glide is not an independent segment. I will therefore assume that the prenuclear $G$ is part of the onset. Specifically, $G$ in GV and GVX is the onset, and G in CGV and CGVX is the secondary articulation of the onset C (cf. Duanmu (1990) for more discussion). 
Many languages show a clear distinction between heavy syllables (two $\mathrm{X}$ slots in the rime, such as CVV and CVC) and light syllables (one X slot in the rime, such as CV). The former may carry inherent stress (cf. Hayes (1980); Halle and Vergnaud (1987); Prince (1992)). For example, in Koya, stress falls on all heavy syllables but not on light syllables (except the initial one) (Hayes (1980), citing Tyler (1969)). Similarly, although word stress in English nouns usually falls on the antepenultimate syllable, if the penult is heavy, it gets the word stress (cf. Halle and Vergnaud, among others). In addition, it is true in general that the more $\mathrm{X}$ slots a word has, the longer it is. In Arabic, for example, the paradigm katab, $k a t t a b$, kaatab are distinguished by segmental durations, i.e., [t] v. [tt] between katab and kattab and [a] vs. [aa] between kata and kaatab. In English, too, a heavy rime (two $\mathrm{X}$ slots), such as a long vowel or a diphthong, is phonetically longer than a light rime (one $\mathrm{X}$ slot), such as a short vowel, so that the vowel in peel is longer than that in pill, and the first rime in citing is longer than that in city.

\subsection{M-languages}

We now turn to Chinese. Consider M-languages first. Parallel to the contrast between heavy and light rimes in other languages, there is a clear distinction between 'full' syllables and 'weak' syllables (sometimes called 'neutral-tone' syllables). A weak syllable usually has a simple rime $\mathrm{V}$, such as the question marker $m a$ or the aspect marker $l e$. In special contexts, a full syllable may be reduced to a weak one, such as in reduplicated words like $n a i^{3} \boldsymbol{n a t}^{3}$ 'grandma' and $\boldsymbol{b a i ^ { 2 }} \boldsymbol{b a t}^{2}$ 'uncle', or in certain fixed words like $d i^{4}$ fang $^{1}$ 'place' and $d o n{ }^{1}{ }^{1} \boldsymbol{x i}^{1}$ 'thing' (weak syllables in boldface). An important point about such words is that when a heavy syllable CVX is reduced to a weak syllable, the coda $X$ is dropped, as reported by Lin and Yan (1988) in their acoustic study of 128 weak syllables. Lin and Yan also found that the average rime duration of a full syllable is on the order of $200 \mathrm{~ms}$, while that of a weak syllable is on the order of $100 \mathrm{~ms}^{6}$ I will, therefore, consider weak syllables as light.

Next consider full syllables. In traditional transcriptions, full rimes in M-languages may be either light (V) or heavy (VX), as seen in the Mandarin words $m a^{51}$ 'to scold' and $m a i^{51}$ 'to sell'. If this is correct, one would expect there to be a distinction between the two rime types, either in terms of stress or in terms of duration. However, there is little evidence for such a distinction. Consider Mandarin rimes. In an acoustic study, Howie (1976) grouped 136 full Mandarin syllables into nine types according to their syllabic structure, and measured the duration of the "voiced 
part" of the syllables. After averaging the duration for each type, he found that the nine syllable types fall into two durational categories: those that have a voiced onset (a glide or one of [ $\mathrm{m} \mathrm{l}]$ ), and those that do not have a voiced onset. The voiced duration of the former is on the order of 300 $\mathrm{ms}$, while that of the latter $200 \mathrm{~ms}$. In Howie's words:

When the actual durations were compared, it was found that for every tone the mean durations of Types 2, 3, and 5 (i.e., $\mathrm{GV}, \mathrm{GVX}, \mathrm{NV}$, where $\mathrm{N}$ is $[\mathrm{mnl}]-\mathrm{S} . \mathrm{D}$.) are from 50 to 60 per cent (i.e., abotu $100 \mathrm{~ms}$ - S.D.) greater than the mean durations of the other types (i.e., those without a voiced onset - S.D.), and that the mean durations of the other types are nearly identical for each tone (i.e., about $200 \mathrm{~ms}-$ S.D.). (p. 216)

Although Howie did not measure the durations of individual segments, it is reasonable to assume that the extra $100 \mathrm{~ms}$ voiced duration in GV, GVX, and NV types (compared with TV and TVX types, where T is a voiceless onset) comes from prenuclear $\mathrm{G}$ or $\mathrm{N}$, which are not in the rime. ${ }^{7}$ In other words, the average rime durations of all syllable types are on the same order of $200 \mathrm{~ms}$. Similar results are reported in Lin et al. (1984), Lin and Yan (1988), and X. S. Shen (1990), among others. ${ }^{8}$

In Cantonese (and other $\mathrm{M}$-languages that have retained [ $\mathrm{ptk}$ ?] codas), there is no durational difference between CV and CVX syllables. Instead, there is a contrast between $\mathrm{Ru}$ syllables (those with [p t k P] codas) and non-Ru syllables. Kao (1971) and $\mathrm{Ng}(1989)$ report that $\mathrm{Ru}$ syllables were generally much shorter than non-Ru syllables. However, as Duanmu (1990) argues, the shortness of Ru syllables is due to two facts. First, the vowel in Chinese $\mathrm{Ru}$ syllables is glottalized (cf. [hot] 'to drink' in Cantonese and [hot] 'hot' in British English), and glottalized sounds are probably intrinsically shorter (just as stops are intrinsically shorter than fricatives). Second, Chinese $[\mathrm{ptk}]$ codas are unreleased and thier durations were rarely measued in previous studies (cf. Kao [1971, 57), Ouyang (1979, $360)$ ), where the durations of $[\mathrm{ptk}]$ codes were considered practically zero). In a recent study of Duanmu (1992d), based on four Cantonese speakers, it was found that, even though Cantonese $[p t k]$ codas were unreleased, they nevertheless had a period of duration. In particular, Duanmu measured the intervocalic voiceless durations in bisyllabic expressions. When a Ru coda was followed by a voiceless onset, the average total voiceless duration was $246 \mathrm{~ms}$. When a Ru coda was followed by a voiced onset, or when a voiceless onset followed an open vowel or a voiced coda, the average voiceless duration was $130 \mathrm{~ms}$. This shows that 
the Cantonese $\mathrm{Ru}$ coda has the same duration as the onset. Taking this into consideration, $\mathrm{Ru}$ syllables should not be considered light, but heavy. ${ }^{9,10}$

With respect to stress, there is again no distinction among full syllables. Any full rime can be stressed, and no full rime type is more likely to be stressed than another type. Similarly, in Chinese poetry, what matters for any given metrical position is just the tone of a syllable and not the segmental structure of a syllable (Wang (1957), Chen (1977)). ${ }^{11}$

The above evidence indicates that full rimes that were traditionally written as [V] are in fact heavy [V:] rimes. That is, all full syllables in $\mathrm{M}$-languages are heavy. Why, then, have open rimes been written as [V] all along)? To my knowledge, there is just one motivation, namely, phonemic economy. Since vowel length is predictable from syllabic structure, namely, short in closed rimes and long in open rimes, it is omitted in order not to double the number of vowels. In the words of Chao (1934/1957), it is for "parsimony in the total number of phonemes." However, in current phonological theory, this reasoning no longer makes sense. Not only does the "parsimony" turn out to be illusory, but it also complicates the analysis. Let us see why.

First, in nonlinear phonology, vowel length need not be represented in the segment, but can be represented in the syllabic structure. We show [an] and [a:] below

(6)
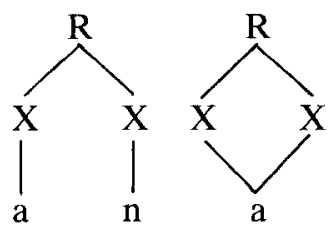

$(\mathrm{R}=$ rime $)$

Timing tier

Segment tier

As seen in (6), a long [a] is an [a] linked to two $X$ slots. Thus, accepting [V:] rimes in M-languages does not double the number of vowels, and no economy is gained by changing [V:] to [V].

Second, if we realize that all full syllables are heavy, then there is a uniform structure for all full rimes, namely a bimoraic rime, as shown in (6). On the other hand, if we write [V:] as [V], we need a monomoraic rime structure, beside a bimoraic one, for full syllables. Besides, this monomoraic 'full' rime confuses with a monomoraic 'weak' rime. Consider

(7) a.

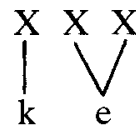

thirsty

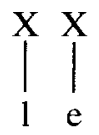

Asp b. $\mathrm{X} \times \mathrm{X} \times$

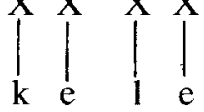

'(sb. is) thirsty' 
There are two differences between $k e$ and le. First, ke has tone, but le does not. Second, the rime in $k e$ is longer than the rime in le. (7a) shows both differences. ( $7 \mathrm{~b})$, however, cannot show the length distinction. Moreover, if we analyze open full syllables as light, we lose the generality that heavy rimes are long and may carry stress, while light rimes are short and get stress only by rule, a generality that is of great importance in metrical phonology.

To conclude, the traditional analysis which regards open full rimes as short/light gains no phonemic economy; instead, it introduces phonological complications. I will, therefore, assume that all full syllables in $\mathrm{M}$ languages are heavy (cf. Duanmu (1990) for arguments in other Mlanguages, such as Cantonese and Xiamen).

\subsection{S-languages}

We look at New Shanghai first. Unlike M-languages, New Shanghai does not display a stress contrast between full and light syllables. ${ }^{12}$ The null hypothesis then is that all New Shanghai syllables have the same weight. If this is so, we ask if they are all heavy or all light. Let us compare the rime inventories of New Shanghai and Mandarin.

(8) Mandarin (Chao $(1968,24)$, excluding prenuclear G)

a. $\begin{array}{llllllll} & \mathrm{r} & \mathrm{i} & \mathrm{u} & \mathrm{u} & \mathrm{a} & \gamma\end{array}$

b. ai ei au ou in an ən in an əy on er

(9) New Shanghai (Xu et al. (1981), excluding prenuclear glides) $)^{13}$

a. $\begin{array}{llllllllllllllllll} & \mathrm{n} & \mathrm{z} & \mathrm{i} & \mathrm{u} & \ddot{\mathrm{u}} & \mathrm{r} & \mathrm{a} & \mathrm{A} & \boldsymbol{o} & \boldsymbol{\jmath} & \gamma & \mathrm{E} & \emptyset & \tilde{a} & \tilde{A}\end{array}$

b. ən in ün on A? or ar i?

I will call those in (8a) and (9a) simple rimes and those in (8b) and (9b) complex rimes. A striking difference between (8) and (9) is that (9) contains more simple rimes. In particular, New Shanghai has lost all diphthongs and many [VN] rimes, as shown by the following cognate words.

(10) a. Mandarin New Shanghai $\begin{array}{lll}\text { [ai] } & \text { [e] } & \\ \text { lai } & \text { le 'come' } \\ \text { ts }^{\text {hai }} & \text { ts }^{\text {he }} & \text { 'guess' }\end{array}$ b. Mandarin New Shanghai

$\begin{array}{lll}\text { [ou] } & {[\gamma]} & \\ \text { lou } & \text { l } \gamma & \text { 'floor' } \\ \text { tsou } & \text { ts } \gamma & \text { 'walk' }\end{array}$




\begin{tabular}{|c|c|c|c|c|c|}
\hline c. [an] & [e] & & d. $|a u|$ & |o] & \\
\hline $\operatorname{lan}$ & le & 'blue' & lao & lo & 'old' \\
\hline fan & ve & 'rice' & $t^{\text {haoo }}$ & to & 'peach' \\
\hline e. [an] & [ãa & & f. [ei] & [e] & \\
\hline $\operatorname{lan}$ & lã & 'wolf' & mei & me & 'coal' \\
\hline $\mathrm{t}^{\mathrm{h}} \mathrm{an}$ & tã & 'sugar' & pei & pe & 'cup' \\
\hline
\end{tabular}

It is still possible, though, that all New Shanghai rimes are heavy; since rimes in (9b) look like heavy ones, the only thing to show is that rimes in (9a) have the same length as (9b). On the other hand, the data in (10) show that New Shanghai is shifting from complex rimes to simple rimes,so there is a possibility that all New Shanghai rimes are light. To establish this, one has to argue that (9b) are simple rimes, at least underlyingly. I will argue for the second possibility.

First, consider the glottal coda [r]. As noted in many studies, the glottal coda in New Shanghai is found only if the syllable is in a final position; in non-final positions, [?] is dropped, while the vowel stays glottalized (Xu et al. $(1981,1988)$ ). This is confirmed by the phonetic study of Duanmu (1992d), who found no voiceless duration for the [?] coda in [CV?] when it is followed by another syllable. In addition, when [P] is dropped, there is no compensatory lengthening of the vowel in New Shanghai, in contrast to the case in Taiwanese, an M-language, where [?] deletion does lead to compensatory lengthening (Tsay (1990)). I will assume, then, that [V?] in (9b) is underlyingly a glottal vowel, which when in a final position, may be lengthened by one $X$ slot, in which [?] can appear.

Next consider the four remaining complex rimes [on in ün on], which all end in a nasal. We note that the low vowels [a A] do not take a nasal coda. For non-low vowels, there is no minimal coda contrast: [n] occurs with the back [o], and [n] with the non-back [o i ü]. It is possible, then, that the [VN] rimes are underlyingly a nasalized vowel $[\tilde{\mathrm{V}}]$. But why are they not all written as $[\tilde{\mathrm{V}}]$, like $[\tilde{\mathbf{a}} \tilde{\mathrm{A}}]$ are? There are two possible answers. First, phonetic studies show that low vowels are more likely to be perceived as nasalized than high vowels (Whalen and Beddor (1989)). Second, the inventory in (9) is likely based on syllables in isolation, where the rime can be lengthened to two moras (the minimal word effect), in which case a nasal may surface in the coda (cf. the glottal coda case). ${ }^{14.15}$ In nonfinal positions, when a syllable is not lengthened, we expect to find $[\tilde{V}]$ instead of [VN]. This prediction is confirmed by a passing note of $\mathrm{Xu}$ et al. (1988, 73), who point out that what they write as [ən in ün on] "are often pro-

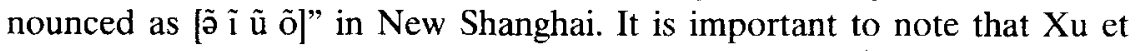


al. did not mention this point in their earlier works (Xu et al. (19811983)). The reason, I believe, is that rime inventories are generally based on isolated syllables, and transcribers do not always talk about what happens to rimes in non-final positions. I leave it open whether in other varieties of Shanghai $[\mathrm{VN}]$ is pronounced $[\tilde{\mathrm{V}}]$ too.

In sum, there is no compelling reason to assume that New Shanghai has heavy rimes underlyingly. Instead, we can analyze (9) as follows

(11) Underlying New Shanghai Rime Inventory $\left(\left[\mathrm{V}^{\prime}\right]=\right.$ glottalized V)

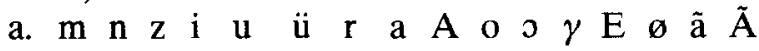

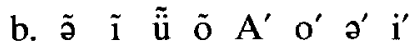

where all rimes are light.

I call (11) the 'underlying' rime inventory of New Shanghai, since in some situations, a rime can be lengthened to two $\mathrm{X}$ slots. ${ }^{16}$ For example, when a rime occurs in an isolated domain, it may gain another $\mathrm{X}$ slot, due to a metrical requirement that a minimal word, or a minimal foot, must at least be two moras long (McCarthy and Prince (1990), Prince (1992)). Similarly, a rime may be lengthened in final position. Since the rime inventory is traditionally based on isolated, stressed syllables, it is natural that, with an extra $X$ slot, $(11 b)$ becomes (9b).

It is interesting to examine some phonetic data here. Zee and Maddieson (1979) measured some New Shanghai syllables in the following environment. ${ }^{17}$

$$
\begin{aligned}
& \text { nu do? } \underline{S} \text { pa? noy } t^{\mathrm{h}} \text { in } \\
& \text { I read give you listen } \\
& \text { 'I read } \underline{\$} \text { for you to listen.' }
\end{aligned}
$$

This environment is an isolated domain. The syllable in question, $\mathbf{S}$, serves as the syntactic object, which is a full XP and forms a tonal domain by itself (cf. Selkirk and Shen (1990)). In addition, since $S$ is changed every time, while the carrier frame remains unchanged, $S$ will carry contrastive stress (cf. Myhill and Xing (1991)). Thus, in our analysis, $\mathbf{S}$ will be lengthened in this environment. Now consider Zee and Maddieson's (1979) measurements (p. 101).

$$
\begin{array}{lllllllll}
\text { rime }^{\text {tone }} & \text { A } & \text { B } & \text { C } & \text { D } & \text { E } & \text { Average } & \\
\text { V } & 262 & 327 & 332 & & & 307 \mathrm{~ms} & \text { (total } 30 \text { tokens) } \\
\text { VP } & & & & 102 & 147 & 125 \mathrm{~ms} & \text { (total } 20 \text { tokens) }
\end{array}
$$


The $\mathrm{V}$ rime (in our view [V:] here) is over twice the duration of the V? rime. But as discussed earlier, this comparison is deceptive in two ways. First, the vowel in V? is glottalized and so is intrinsically shorter than a nonglottal vowel. Second, no duration is given to the global coda [?]. If we add $100 \mathrm{~ms}$, which is the normal duration of a voiced segment like [y w $\mathrm{n} \mathrm{m}$ ] in such an environment, for the silent duration of the [?] coda, then the V? rime comes close to the $\mathrm{V}$ rime. ${ }^{18}$

In non-isolated domains, we predict that the New Shanghai rime will be light and its duration reduced by half, in the order of $100 \mathrm{~ms}$ with contrastive stress (as in a repeated carrier frame), or slightly shorter without contrastive stress (as in a spontaneously composed sentence). In contrast, a full rime in an M-language should remain heavy even in a non-isolated, noncontrastive environment. In other words, in normal speech, most New Shanghai syllables will be CV (two X slots), and most Mandarin syllables will be CVX (three $\mathrm{X}$ slots). Now if this is the case, we are predicting that the Shanghai speaker will utter syllables at a considerably faster speed than the Mandarin speaker will. This is a startling prediction and to my knowledge has never been made before. Nevertheless, a preliminary study by Duanmu (1992d) has provided supporting evidence.

Duanmu's (1992d) experiment was as follows. Five sentences, containing a total of 55 full syllables and no weak ('neutral tone') syllables, were read by three Mandarin speakers, and each speaker read the sentences four times in random order. With slight changes to accommodate dialectal vocabulary, the five sentences, still containing 55 syllables, were then read by five Shanghai speakers, and each of those speakers read them four times in random order. The total number of syllables read by each speaker was 220 . All speakers were instructed to read at normal speed, without pauses or swallowing syllables. The average syllable duration of each speaker was calculated by dividing the total sentence durations by the total number of syllables. The results are as follows (M1, M2, . ., SH1, SH2, . , are speakers; measurements are in $\mathrm{ms})$.

(14) Comparative average syllable durations in normal speech:

$\begin{array}{llllllll}\text { Mandarin } & \text { M1 } & \text { M2 } & \text { M3 } & & & \text { Average } \\ & 211 & 201 & 218 & & & 210(\mathrm{~ms}) \\ \text { Shanghai } & \text { SH1 } & \text { SH2 } & \text { SH3 } & \text { SH4 } & \text { SH5 } & \text { Average } \\ & 176 & 166 & 151 & 170 & 146 & 162(\mathrm{~ms})\end{array}$

Two comments can be made. First, although speakers vary in speed, the fastest Mandarin speaker (201 ms) is still considerably slower than the 
slowest Shanghai speaker $(176 \mathrm{~ms})$. Second, the difference between the average syllable durations in the two languages $(210 \mathrm{~ms}$ vs. $162 \mathrm{~ms})$ is significant enough to support our analysis that full Mandarin syllables have one more $\mathrm{X}$ slot than Shanghai syllables. The fact that the average Shanghai syllable is slightly longer than two thirds of the average Mandarin syllable (i.e., not $140 \mathrm{~ms}$, but $162 \mathrm{~ms}$ ) may be due to two reasons. First, a long vowel or a diphthong is not always twice as long as a monophthong. Second, some of the Shanghai syllables may have been lengthened due to their domain-final positions, which may have increased the average duration. ${ }^{19}$

I have often heard non-linguists say that Shanghai speakers talk fast. Our analysis provides both concrete evidence and theoretical explanation for the lay person's impression. One should not, however, rush to conclude that to convey the same idea, the Mandarin speaker must talk longer than the Shanghai speaker. This is because in causal speech, many syllables can be destressed and/or swallowed, and more work is needed for understanding faster, causal speech.

\subsection{A Generalization}

Let us summarize our discussion so far. I have argued that full rimes in M-languages are heavy for the following reasons.

(15) a. There is a stress contrast between full and weak syllables.

b. Full syllables do not have intrinsic stress contrasts among themselve.

c. Some full syllables have complex rimes, such as diphthongs, minimal [ $\mathrm{m} \mathrm{n} \mathrm{ng],} \mathrm{and/or} \mathrm{minimal} \mathrm{[p} \mathrm{t} \mathrm{k} \mathrm{?]} \mathrm{coda} \mathrm{contrasts.}$

d. Full syllables have similar rime durations $(150-200 \mathrm{~ms}$ depending on environment), which are twice that of weak syllables.

I have also argued that all syllables in New Shanghai are underlyingly light for the following reasons.

(16) a. There is lack of stress contrast between full and weak syllables.

b. All rimes are simple.

c. In non-isolated, noncontrastive environments, the rime duration is about $70-80 \mathrm{~ms}$.

Our discussions have focused on Mandarin and New Shanghai, regarding which there is a fairly rich phonetic and phonological literature. For 
other major M-languages, such as Tianjin, Cantonese, Fuzhou, Taiwanese, etc., there is also sufficient literature showing that they match $(15 \mathrm{a}-\mathrm{d})$, although the literature on (15d) is meager. For lesser known M-languages and most other S-languages, both phonological and phonetic descriptions are sparse. Indeed, since for the majority of Chinese languages there is little description of their tone sandhi, we cannot even tell whether they are $\mathrm{M}$-languages or S-languages. Nevertheless, for those languages whose tone sandhi and rime structures are sufficiently documented, an important generalization can be made:

(17) a. All M-languages have complex rimes.

b. All S-languages have simple rimes only.

As $I$ have shown in the discussion of New Shanghai, traditional transcriptions should not be taken at their face value. What is transcribed as a complex rimes may turn out to be a simple rime. I propose two criteria for judging whether a language has complex rimes.

(18) a. Are there diphthongs?

b. Do codas contrast in $[\mathrm{m} \mathrm{n} \mathrm{n}]$ or $\left[\mathrm{p} \mathrm{t} \mathrm{k} \mathrm{r} \mathrm{]} ?^{20}\right.$

If a language meets either (18a) or (18b), it has complex rimes. If a language meets neither of $(18 \mathrm{a}, \mathrm{b})$, it has simple rimes only. Below are some examples (cf. Chao (1928), Zhu et al. (1986), HYFYZH (1989)).

$\begin{array}{llll} & \text { Coda contrast } & \text { Diphthongs } & \text { Tone sandhi } \\ \text { Cantonese } & + & + & \mathrm{M} \\ \text { Xiamen } & + & + & \mathrm{M} \\ \text { Meixian } & + & + & \mathrm{M} \\ \text { Mandarin } & + & + & \mathrm{M} \\ \text { Fuzhou } & + & + & \mathrm{M} \\ -\mathrm{-} & + & - & \mathrm{S} \\ \text { New Shanghai } & - & - & \mathrm{S} \\ \text { Old Shanghai } & - & - & \mathrm{S} \\ \text { Suzhou } & - & - & \mathrm{S} \\ \text { Danyang } & - & - & \mathrm{S} \\ \text { Shanoxing } & - & - & \mathrm{S}\end{array}$

All languages above the line have complex rimes. All languages below the line have simple rimes only. For illustration, compare the rime inventories of Suzhou, Danyang, and Cantonese (excluding prenuclear G). 
(20) Suzhou (Yuan $(1989,59))$

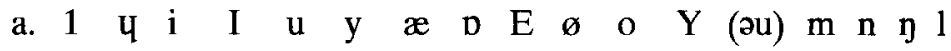
b. on in un yn an on on $\mathrm{P}$ a? $\mathrm{D}$ ? $\gamma$ ? $\mathrm{o}^{\mathrm{r}}$

(21) Danyang (Lü $(1980,86))$

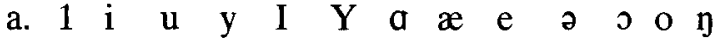
b. in yy an en on on if a? $x ?$ o?

\section{Cantonese (HYFYZH (1989))}

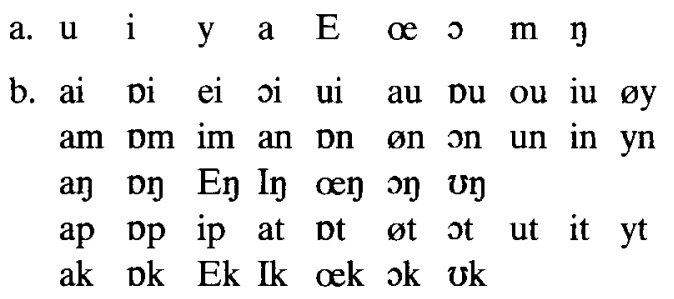

For Suzhou, Yuan does not say whether [V?] in (20b) drops the [?] in non-final positions. But since suzhou is a $\mathrm{Wu}$ language, and since [P]-drop is a general Wu phenomenon (Chao (1967)), [VP] can be analyzed as a glottal vowel [V']. Similarly, [n n] do not contrast, so [VN] can be analyzed as [ $\tilde{\mathrm{V}}$, as I argued for in New Shanghai. This agrees with Yuan's own observation that "strictly speaking," [ay py] can be transcribed as [ã $\tilde{~}]$ (p. 61). However, since Yuan does not say whether other [VN] rimes alternate with [ $\tilde{V}]$, especially in non-final position, I have to leave it open. Turning to diphthongs, the only one in Suzhou is [əu], which Yuan puts in parentheses. As Yuan notes, $[\mathrm{u}]$ and $[\mathrm{vu}]$ are in complementary distribution, "therefore $[\mathrm{u}]$ and $[\partial u]$ can be regarded as alternants of the same rime;" in addition, $[\mathrm{p}]$ in $[\mathrm{\partial u}]$ is "short" and "transitory," so [ou] is phonetically [a] (p. 62 ). Thus, Suzhou has neither diphthongs nor minimal coda contrasts; all its rimes are simple.

Next consider Danyang, another Wu language. Here again, the only

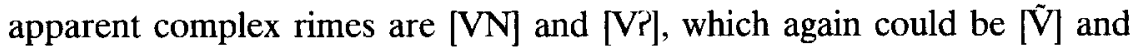
$\left[\mathrm{V}^{\prime}\right]$ underlyingly. Thus, Danyang, too, has simple rimes only.

Finally, consider Cantonese. First, we see diphthongs [ai ei ui ... .]. Then we see minimal coda contrasts, such as [am an] and [ap at ak]. Thus, Cantonese has complex rimes.

The most striking aspect of (19) is that there is a systematic correlation between rime structure and tone sandhi. All languages that have complex rimes are $\mathrm{M}$-languages, i.e., their phrasal tone cannot be predicted from any single syllable, while all languages that have just simple rimes are 
S-languages, i.e., their phrasal tone is largely determined by the initial syllable (cf. Zee and Maddieson (1979), Xu et al. (1981-1983), Xu et al. (1988), Selkirk and Shen (1990) for New Shanghai; Sherard (1972), T. Shen (1981a, 1982), Xu et al. (1988) for Old Shanghai; Ye (1979), Xie (1982), Qian and Shi (1983) for Suzhou; Lü $(1947,1980)$ for Danyang; F. Wang (1959), H. Wang (1991) for Shaoxing; Ao (1992) ${ }^{21}$ for Nantong). To my knowledge, this correlation holds for all Chinese languages that are sufficiently documented. I consider this correlation to be not an accident but a significan discovery. As I will show below, this correlation, together with independent metrical principles, pieces together a variety of tonal patterns in Chinese languages (such as Mandarin, Danyang, Suzhou, Old Shanghai, and New Shanghai) and gives them a unified explanation.

\section{STRESS}

We will discuss three aspects of stress that are of interest to our topic: its relation to rime length, its relation to syllable tone, and its relation to domains of tonal association.

\subsection{Stress and Rime Length}

The relation between stress and rime length has long been recognized in metrical phonology. Summarizing previous results, Prince (1992, 358) proposes the following universal principle. ${ }^{22}$

\section{The Weight-to-Stress Principle (WSP)}

If heavy, then stressed. (If unstressed, then light.)

The WSP is a well-formedness condition on the output. There are two ways to satisfy it. First, one may place stress on all heavy rimes during stress assignment. Alternatively, if some heavy rimes fail to get stress, they must be converted to light syllables, by shortening the vowel or dropping the coda. The fact that unstressed Mandarin syllables drop their codas, as reported by Lin and Yan (1988), can be seen as a result of the WSP. That heavy rimes attract stress are shown in the examples below.

(24) Koya (Hayes (1980, 98), citing Tyler (1969)):

Primary stress falls on the initial syllable, and secondary stress on closed syllables or syllables with a long vowel.

(25) Huasteco (Hayes (1980, 98), citing Larsen and Pike (1949)):

Stress the rightmost long vowel, otherwise the initial syllable. 
(26)

\section{Latin Stress:}

Stress the penult if it is heavy. Otherwise stress the antepenult.

Besides the WSP, there is a general tendency to avoid a foot that consists of only a monomoraic syllable. The common solution is either to lengthen such a foot to a bimoraic syllable or not to assign stress on it (i.e., consider it a degenerate foot). In English, for example, there are no openclass CV words; all monosyllabic open-class words are either closed syllables, or they contain a long vowel. In addition, when such closed-class words as to, the and $a$ are stressed, they become heavy [tu:], [ði:] and [ei]. Cf. Prince (1992), Hayes (1992) for more examples and references.

\subsection{Stress and Syllable Tone}

There is a general tendency for a stressed element to keep its features and for an unstressed element to lose some of its features. One such case is English vowel reduction, by which a stressless vowel may lose its height and frontness to become a schwa. Similarly, stressless vowels may lose voicing in Southern Paiute (Halle and Clements (1985)) and Chatino (Kenstowicz and Kisseberth (1979), citing Gleason (1955)). It is natural, therefore, that a stressless syllable may lose its tones, as shown by the Mandarin words below $(*=$ stress).

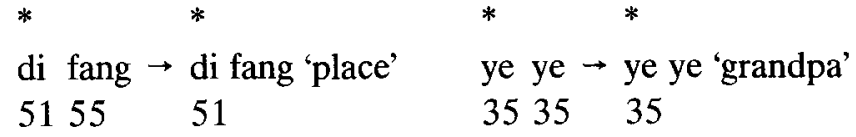

In (27), only the first syllables are stressed, and they keep their tones. The second syllables are unstressed and lose their tones.

\subsection{Stress and the Association Domain (AD)}

By 'association domain' (AD) I mean a domain in which tones may shift and spread, if the domain has more than one syllable. For example, (2a4) are ADs, since the second syllable gets its surface tone from the first syllable after its own tones are deleted. We show (2a) below. ${ }^{23}$

$$
\begin{aligned}
& \text { LH HL LH L } \mathrm{H} \\
& \mathrm{sz}+\mathrm{pe} \rightarrow \mathrm{sz}+\mathrm{pe} \rightarrow \mathrm{sz}+\mathrm{pe} \text { 'nine cups' } \\
& \begin{array}{lllll}
34 & 53 & 34 & 33 & 44
\end{array}
\end{aligned}
$$

It should be emphasized that not all sandhi domains are ADs. For example, the domain of Mandarin Third Tone Sandhi [214214] $\rightarrow$ [35 214] is not an $\mathrm{AD}$, since there is no shifting or relinking of tone from 
one syllable to another. Similarly, sandhi domains in Min languages (as discussed in Chen (1987) for example) are not ADs, since, again, there is no shifting or relinking of tones across syllables. On the other hand, the Mandarin tone sandhi below happens in an $\mathrm{AD}$, since the surface $\mathrm{H}$ on $l e$ comes from mai.

$$
\begin{aligned}
& \text { MLH ML H } \\
& \text { mai le } \rightarrow \text { mai le buy Asp ('bought') } \\
& 214 \quad 21 \quad 44
\end{aligned}
$$

One important property of the AD is that it is sensitive to syntactic relation. For example, SV (subject verb) or VO (verb object) never form an AD in Wu languages. In contrast, the Mandarin Third Tone Sandhi can apply to two syllables of any syntactic relation, including SV $\left[\mathrm{wo}^{214} \mathrm{mai}^{214}\right]$ $\rightarrow$ [35 214] 'I buy' and VO [mai $\left.{ }^{214} \mathrm{ma}^{214}\right] \rightarrow[35214]$ 'to buy horses'.

Another important property of the $\mathrm{AD}$ is that it is sensitive to stress. In particular, a contrastive stress may break an $\mathrm{AD}$ into two, as shown in New Shanghai below (parentheses $=\mathrm{AD}$, underline $=$ contrastive stress, $V^{\prime}=$ glottalized $V$ ).
(30) a. (zã-he da-fió)
Shanghai big-school
b. (zã-he) (da-ho')
'Shanghai University'
Shanghai big-school
'Shanghai University'

The expression for 'Shanghai University' usually forms one AD, as in (30a). But when a contrastive stress is put on $d a$, as in 'not Shanghai Middle school, but Shanghai University', then the expression breaks into two ADs, as in (30b).

What determines the $\mathrm{AD}$ in $\mathrm{Wu}$ languages? What makes the initial syllable keep its underlying tones (which may later shift to others), and non-initial ones lose their underlying tones? Let us consider two theories.

The first theory, which I will call the Stress-Domain theory, holds that an $\mathrm{AD}$ is a stress domain (Yip (1980), Wright (1983), Duanmu (1991), (1992c), among others). In particular, in New Shanghai left-headed stress is assigned to the initial syllable, which then keeps its tones, while other syllables lose their tones. This theory analyzes (30) as follows.

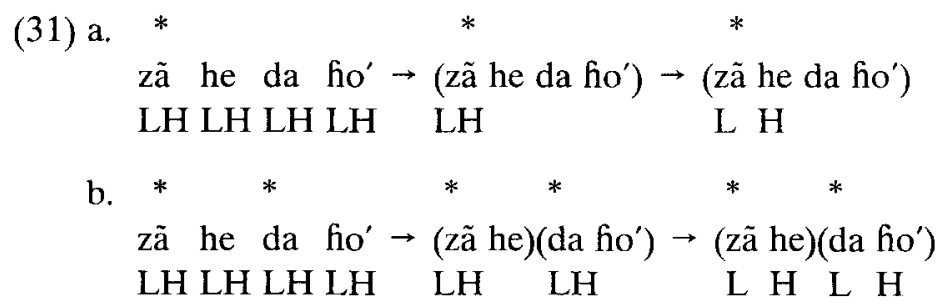


In (31a), the only stress is on $z \tilde{a}$, and so there is one $\mathrm{AD}$. And only the tones from $z \tilde{a}$ are preserved and then linked to the first two syllables; the last two syllables may remain toneless or get default $\mathrm{L}$, which I will ignore. In (31b), there are two stresses, the one on $d a$ being contrastive stress, and hence there are two ADs. The tones are then spread out in the same manner.

The second theory, which I will call the End-Domain theory, holds that the $\mathrm{AD}$ is determined not by stress, but by a positional parameter [Left, Lex ${ }^{0}$, which says that a domain starts from the left end of a lexical word, followed by a rule that deletes all tones except the first two (Selkirk and Shen $(1990,319-320)$ ). This rule is given in (32), with the analysis of (30a) in (33)

(32) Obligatory Tone Deletion (Selkirk and Shen, 319)

$$
\begin{aligned}
& \left(\mathrm{T}^{1} \mathrm{~T}^{2} \mathrm{~T}^{3} \ldots \mathrm{T}^{\mathrm{n}}\right) \rightarrow\left(\mathrm{T}^{1} \mathrm{~T}^{2}\right) \\
& {[\mathrm{zã} \text { he da ho' } \rightarrow[\text { zã he da ho' }] \rightarrow} \\
& \text { LH LH LH LH LH LH LH LH } \\
& {[\text { zã he da ho'] } \rightarrow \text { [zã he da ho'] }} \\
& \text { LH } \quad \text { L H }
\end{aligned}
$$

The expression in (33) is considered one lexical word. First, the parameter [Left, Lex $\left.{ }^{0}\right]$ places a bracket on the left end of the expression. Then the right end bracket is automatically added. Next (32) applies, deleting all tones but the first two, which are then linked to the first two syllables. Selkirk and Shen do not discuss how they handle (30b), however.

A central difference between the two theories is whether there is domain-initial stress. Selkirk and Shen argue that the initial syllable in New Shanghai shows little phonetic stress, even though initial stress has been suggested previously (e.g., Yip (1980), Wright (1983)). On the other hand, initial stress is reported in at least some Wu languages, such as Danyang (Lü (1980)). It is important to realize, however, that the StressDomain theory does not have to depend on phonetic stress. Instead, it suffices to show that there is phonological stress, or metrical prominence, on the initial syllable. Before we look at evidence for phonological stress, let us look at two questions that face the End-Domain theory.

First, why should contrastive stress start a new AD in (30b)? Clearly, the End-Domain theory must acknowledge that stress can start an $\mathrm{AD}$. But then there is a redundancy problem: an $\mathrm{AD}$ can be created either by the end settings [Left, Lex $\left.{ }^{0}\right]$ or by stress. This begs the question of what relation there is between $\left[\right.$ Left, $\left.\operatorname{Lex}^{0}\right]$ and stress. 
Second, why should the first 10 tones in an $A D$ be kept while all the others are deleted? We know that it is the underlying tones of the initial syllable that are kept. But the End-Domain theory cannot say that we keep the tones from the initial syllable. This is because the end-settings $\left[\right.$ Left, Lex $\left.{ }^{0}\right]$ are unrelated to tone deletion, so there is nothing special about the initial syllable. The fact that New Shanghai keeps the tones from the initial syllable is just an accident. Indeed, the End-Domain theory predicts that it is just as possible for a language with the same settings [Left, Lex $\left.{ }^{0}\right]$ to keep the last two tones, or the first three tones, and so on. However, no such language has been reported. Moreover, there is evidence in Lhasa Tibetan (Duanmu (1992a)) and Nantong (Ao (1992)) that it is indeed the tones of the initial syllable, and not just the first two tones, that are kept. Let us look at Lhasa Tibetan for illustration.

The tonal pattern of an $\mathrm{AD}$ in Lhasa Tibetan resembles that of New Shanghai, namely, it is determined by the domain-initial syllable. According to Duanmu (1992a), Lhasa Tibetan has two underlying syllable tones, $\mathrm{H}$ and LH. In multisyllabic domains, there are just two patterns, as shown below.
(34) a. HH...H
b. LH...H

When the initial syllable is $H$, the $A D$ is (34a), i.e., every syllable is $H$. When the initial syllable is $\mathrm{LH}$, the $\mathrm{AD}$ is (34b), i.e., the first syllable is $\mathrm{L}$, and the rest syllables are H. (34) can be analyzed in the following way.

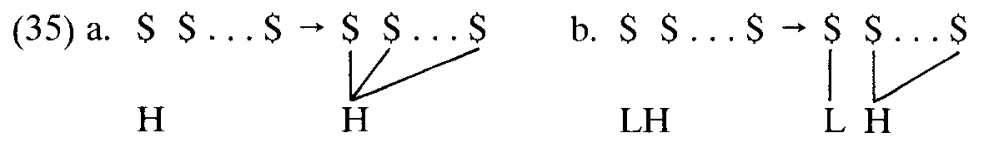

First we delete tones from non initial syllables (as in New Shanghai), so that (35a) is left with $\mathrm{H}$ and (35b) with LH. Then we link tones to syllables one-to-one and left-to-right. Finally, we spread the last tone to remaining syllables. Now, in the End-Domain theory, there is no easy way to state the tone deletion rule without mentioning the initial syllable. In particular, if the deletion rule keeps the first tone, then (35b) should come out as [ $\mathrm{L} L \ldots \mathrm{L}]$, and if the deletion rule keeps the first two tones, then (35a) should vary depending on the tone of the second syllable. Either way, the prediction is wrong.

For the Stress-Domain theory, neither question poses a problem. The stress on the initial syllable enables it to keep its tone(s), whether it has one or more than one tone. Second, since an AD is a stress domain, it follows that any other stress may start a new $\mathrm{AD}$.

Let us now look at metrical evidence for initial stress in $\mathrm{Wu}$ languages. 
We will consider two cases: the word length effect and contrastive stress. First, consider the word length effect in New Shanghai.
(36) a. (sã fo'-ÿü)
b. ${ }^{*}($ sã) $($ fกo'-ÿü)
business school
'business school'
(37) a. (nü-yi fo'-ÿü)
b. (nü-yi)(ho'-ÿü)
language school
'language school'

In general, for [A N] (modifier-noun) structures, [1 2] (monosyllabic + bisyllabic) expressions can only form one $A D$, as shown in (36), while [2 2] (bisyllabic + bisyllabic) expressions may form either one or two ADs, as shown in (37). This asymmetry poses a problem for the End-Domain theory. Since (36) and (37) have the same structure, they are either both made of one Lex ${ }^{0}$, or both made of two Lex ${ }^{0} \mathrm{~s}$. In the first case, both should form one $\mathrm{AD}$, and in the latter case, both should form two ADs. Either way, the prediction is wrong. In the Stress-Domain theory, on the other hand, there is no problem. What we need to do is to assign leftheaded stress cyclically, applying Clash Resolution obligatorily and Stress Reduction optionally (cf. Hammond (1984), Halle and Vergnaud (1987), Haraguchi (1991), among others). (38)-(39) show the derivations of (36) -(37) respectively [ ] = syntactic domains, ( ) $=\mathrm{AD},{ }^{*}=$ stress)

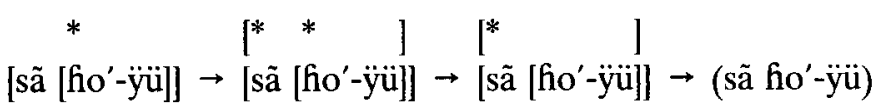

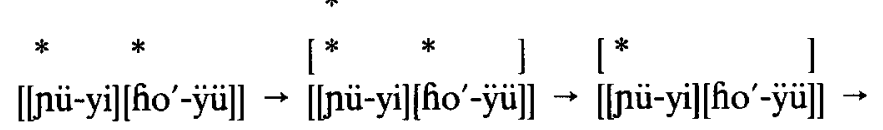

$$
\text { (nü-yi fo'-ÿu) }
$$

b.

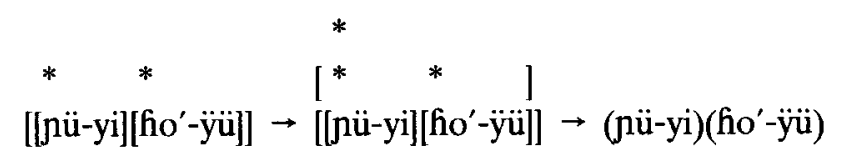

In (38), $6 o^{\prime}$ gets stress on the first cycle, and $s \tilde{a}$ gets greater stress on the second cycle. Since the two stressed syllables are adjacent, Clash Resolution removes the weaker one from $f o^{\prime}$. This leaves $s \tilde{a}$ the only stressed syllable, and (38) forms one AD. In (39), nü and $h o^{\prime}$ get stress on the first cycle. An additional stress is placed on $n \ddot{u}$ on the second cycle. 
Now since the stressed syllables are not adjacent, Clash Resolution does not apply. However, we may apply Stress Reduction (especially in fast speech), which deletes the lowest line of stresses, leaving one stress on $n \ddot{u}$ and giving one $\mathrm{AD}$, as in (39a). If we do not apply Stress Reduction, we have two stressed syllables and hence two ADs, as in (39b). Similarly, consider the following.

$$
\begin{array}{rlr}
\text { (40) a. } & \text { (wã tço-z } \gamma) & *(\text { wã)(tço-z } \gamma) \\
& \text { Wang professor } & \\
& \text { 'Professor Wang' } & \\
& & \\
\text { b. } & (₹ \gamma \text {-yã tço-z } \gamma) & (₹ \gamma \text {-yã) }(\text { tço-z } \gamma) \\
& \text { Ou-yang professor } & \\
& \text { 'Professor Ou-yang' } &
\end{array}
$$

The problem in (40) is the same as that in (36)-(37). For the EndDomain theory, $(40 \mathrm{a}, \mathrm{b})$ are either both made of two lexical words, hence both forming two ADs, or both are compounds, hence both forming one AD. Again, either way the prediction is wrong. (40a) can not form two ADs, whereas (40b) may form either one or two ADs. In the StressDomain theory, the analysis is exactly the same. (40a) is [1 2], so it is like (36). (40b) is [2 2], so it is like (37). The correct analysis crucially depends on Clash Resolution and Stress Reduction, which are trademarks of stress rules.

Let us now consider the second case for metrical stress. We have seen that contrastive stress may create a new AD. This, however, does not always happen. Consider New Shanghai again.
Normal
Contrastive
a. $(\mathrm{k} \gamma \mathrm{t} \gamma)$ dog head
'dog's head'
$(\mathrm{k} \gamma t \gamma)$
(lo-fu t $\gamma$ ) tiger head
$(\mathrm{lo}-\mathrm{fu})(t \gamma)$
'tiger's head'

In normal speech, $(41 \mathrm{a}, \mathrm{b})$ each forms one $\mathrm{AD}$. When there is contrastive stress on the word for 'head', (41b) breaks into two ADs, yet (41a) remains one $\mathrm{AD}$. Again, this asymmetry is unexplained in the EndDomain theory. In the Stress-Domain theory, there is again a simple answer. In (41a), the contrastive stress clashes with the initial stress, so it 
is removed by Clash Resolution, and no new $\mathrm{AD}$ is created. In (41b) the contrastive stress does not clash with the initial stress, so it stays and creates a new $\mathrm{AD}$.

If there is no initial stress in New Shanghai, it is hard to explain the asymmetry in (36)-(37), (40a, b), and (41a, b).

Before we leave this section, let us consider one more piece of evidence for stress. Consider (42) and (43).
a. (ku er) (pa tço fu) 'Gorbachev'
b. (Pe se') (nu pi ya) 'Ethiopia'
*
* *
c. $(\mathrm{x} x)(\mathrm{x} x)(\mathrm{x})$

(43) a. (ço ku r) (pa tço fu) 'small Gorbachev (Gorbachev junior)'

b. (tõ Pe se') (yn pi ya) 'east Ethiopia'

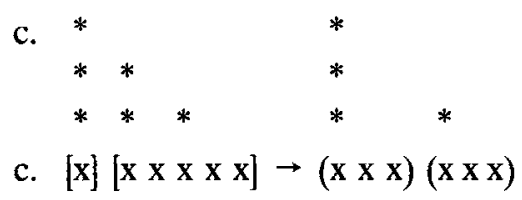

$(42 \mathrm{a}, \mathrm{b})$ are single morphemes, yet they may form two ADs (they may also form one AD in fast speech, where Stress Reduction applies). This is unexplained in the End-Domain theory since each morpheme has just one left edge. In the Stress-Domain theory, (42a, b) may be derived by assigning trochaic stress on Line 1 and left-headed, unbounded stress on Line 2 and ignoring the final degenerate foot, as shown in (42c) (cf. Section 4.2 below). More strikingly, when a monosyllabic morpheme is added at the beginning, as shown in $(43 a, b)$, the expressions still form two ADs, but with the first morpheme and the first two syllables of the second morpheme in the first $A D$ and the remaining three syllables of the second morpheme in the second AD. This again is totally unexplainable in the End-Domain theory. In the Stress-Domain theory, however, the analysis is simple. Each morpheme first undergoes its own stress assignment (trochee on Line 1 and left-headed on Line 2). Then greater stress is assigned to the first morpheme. Now the stress columns on the first two syllables clash, and that on the second syllable is removed. This leaves two stressed syllables, giving two ADs, as shown in (43c). For more discussion against the End-Domain theory, cf. Duanmu (1992c). 


\subsection{Summary}

We have discussed three aspects of stress in its relation to rime structure and tone. I repeat the conclusions below.

(44) a. Weight-to-Stress Principle: If heavy, then stressed.

b. A stressless syllable may lose its underlying tones.

c. A tonal Association Domain (AD) is a stress domain. It starts from a stressed syllable and extends up to just before the next stressed syllable.

One may wonder why the $\mathrm{AD}$ is left-headed, i.e., why it does not start from a stressless syllable and end right after a stressed syllable. In our analysis, this is because the lowest line of stress (at the morpheme level) is trochaic, which is left-headed, and the $\mathrm{AD}$ follows the metrical constituents.

\section{TONE SANDHI}

We begin with tonal representation. I will assume that all contour tones (at the lowest level) are made of level tones, e.g., rise $=\mathrm{LH}$, fall $=\mathrm{HL}$, and fall-rise $=\mathrm{HLH}$, etc. I will, however, not discuss tonal register, since it is irrelevant to our topic.

Next consider the tone bearing unit (TBU). Since there is little doubt that onsets do not bear tones, I will consider two possibilities.

(45) a. The TBU is a moraic segment (i.e., an X slot in the rime).

b. The TBU is the rime as a whole.

The two views differ in that, for (45a), [pa:], [pai], and [pan] have two TBUs each (counting a long vowel as two moraic segments), whereas for (45b) [pa:], [pai], and [pan] each count as one TBU.

Many African tone languages have $\mathrm{CV}$ syllables only and are neutral to $(45 \mathrm{a}, \mathrm{b})$. However, some African tone languages have both $\mathrm{CV}$ and $\mathrm{CVC}$ syllables, and here evidence supports (45a). Consider LuGanda (Clements (1986)).
(46) a. kùlábà
'to see'
b. kùlábìká
'to be visible'
c. kùlábìrízá
'to delay'
d. kùsítùkásítúká
'to be restless' 
(47) a. kùkáàbá

b. kùlínná

c. kùcóppá

d. kùbbiká

e. kùlínnírírá 'to cry'

'to climb'

'to become a pauper'

'to dip'

'to trample on'

The basic pattern has four tones LHLH, as shown in (46), with the final $\mathrm{H}$ spreading to excess syllables. (47a) shows that a long vowel [aa] carries two tones. (47b) shows that the third tone L must be carried by the coda [n] of the second syllable [lin]. (47c) shows that the third tone L must be carried by the coda $[\mathrm{p}]$ of the second syllable [cop], even though $[\mathrm{p}]$ is an obstruent. (47d) shows that the second tone $\mathrm{H}$ must be carried by the coda of the initial syllable [kub]. And so on. (47) suggests that the TBU is each $\mathrm{X}$ slot in the rime and not the rime as a whole. If the TBU were the rime as a whole, (47) would be unaccounted for.

It has been suggested, however, that Chinese languages are typologically different from African languages in that in Chinese, the TBU is the rime as a whole, whereas in African languages, the TBU is the mora (e.g., Yip (1980), (1989), (1992); Bao (1990), Chen (1992)). While it is conceivable that some languages choose (45a) and others choose (45b), in my view evidence for (45b) has not been strong. I will therefore assume (45a) as the only possibility. Our discussion below provides further support for this assumption.

\subsection{Mandarin}

Let us now see why in Mandarin the tone of every regular syllable contributes to the phrasal pattern. We discussed in Section 2 that all regular Mandarin syllables are heavy. We also discussed in Section 3 that heavy syllables may carry inherent stress; this agrees with the fact that all regular Mandarin syllables are stronger than the so called 'neutral tone' syllables, or stressless syllables, such as the aspectual marker $l e$ and the possessive marker $d e$. Moreover, we discussed in Section 3 that a stressed syllable retains its underlying tone and that an $\mathrm{AD}$ is a stress domain. Thus, in Mandarin, evey regular syllable starts an $\mathrm{AD}$. Below is the derivation of (3a). (For exposition, I translate the Mandarin tones from the Chao numbers [55 35214 51] into [H MH MLH HL] respectively; I also omit the $\mathrm{X}$ slots for onsets). 
(48)

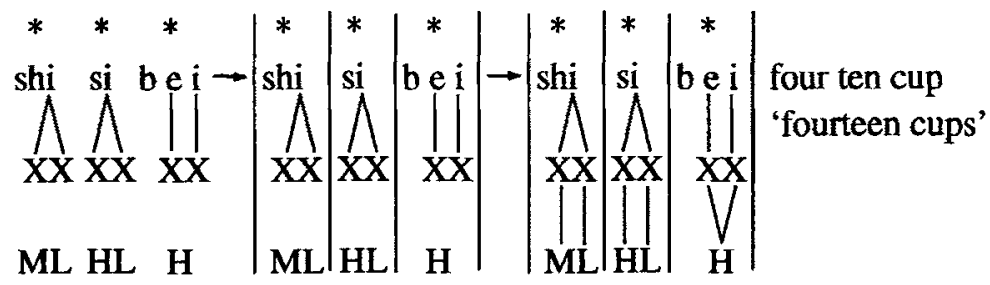

In (48), all syllables are heavy and carry inherent stress, giving three $\mathrm{ADs}$ (shown by vertical lines). In each $\mathrm{AD}$, tones associate to the TBUs (rime slots here $)^{24}$ in the familiar ways. Next consider (49)-(52).

(49)

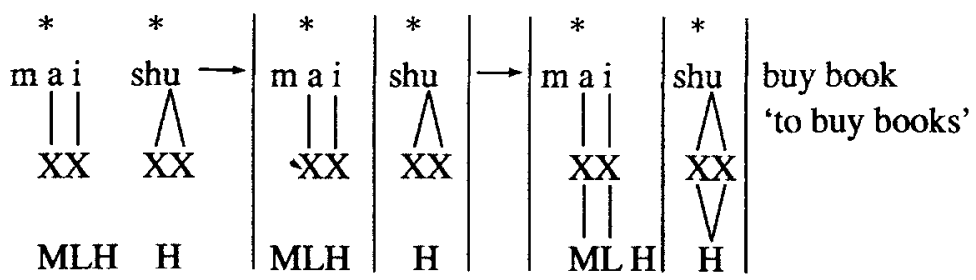

$(50)$

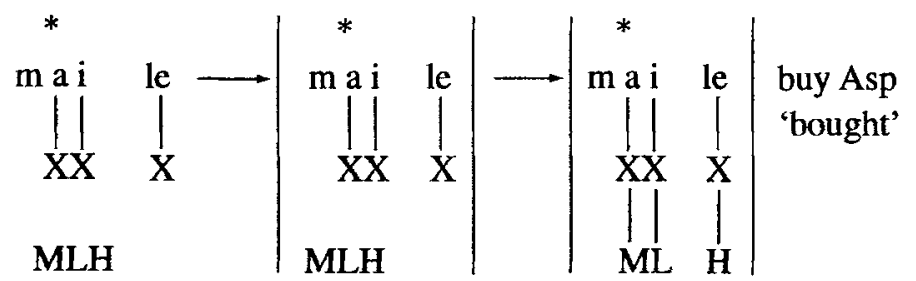

(51)

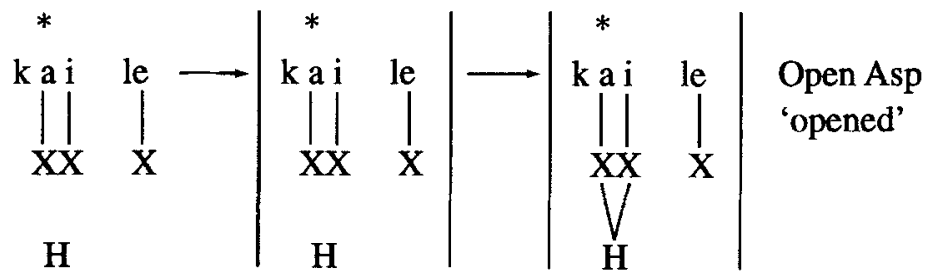

(52)

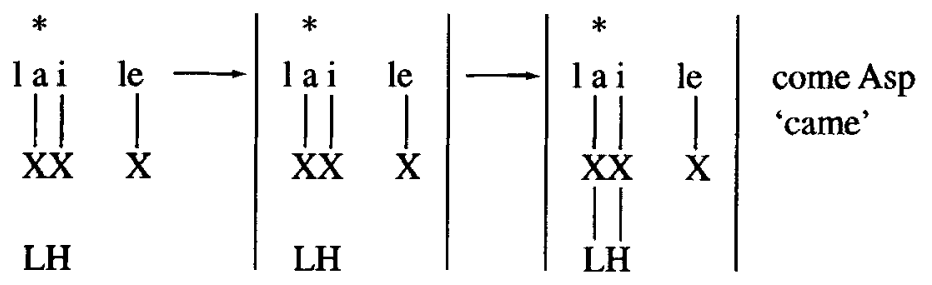

In (49), both syllables are stressed, giving two ADs. Note that mai has three tones, but only two can be linked; the third tone $H$ cannot be linked to shu since shu is in a different AD, even though shu has two TBUs but just one tone. In (50), only mai is stressed, giving one AD. This time the 
third tone $\mathrm{H}$ of mai can link to the toneless le because both words belong to the same $\mathrm{AD}$. In (51), there is again just one $\mathrm{AD}$. The $\mathrm{H}$ spreads over $k a i$ but not to le. Here I will assume that spreading in Mandarin is confined to stressed TBUs, i.e., the first syllable; le may remain toneless or get $\mathrm{L}$ as default. Finally, in (52), there is again one domain. lai has two TBUs, taking up both tones; again there is no spreading to the stressless le.

\subsection{New Shanghai}

I argued in Section 2.2 that all New Shanghai rimes are light. Therefore no New Shanghai syllable carries inherent stress. However, the initial syllable may get stress by rule. Thus only the initial syllable retains its underlying tones and determines the phrasal tone. Let me now state exactly how stress is assigned in New Shanghai. Following Halle and Vergnaud (1987) and Hayes (1992), I propose the following rules.

(53) a. Morpheme level:

Line 0: trochee, left to right, ignore degenerate foot

Line 1: left-headed, unbounded stress

b. Compound level: Assign cyclic left-headed stress

c. Phrasal level: Assign cyclic right-headed stress

d. Stress Reduction: Optionally delete Line 1 stress

e. Clash Resolution: Remove the stress column next to a higher column.

$(53 b, c)$ are similar to the Compound Stress Rule and the Nuclear Stress Rule in English (Halle and Vergnaud (1987), Hayes (1992), among others). (53d, e) are also general stress rules and will not be further justified here. Evidence for (53a) is seen in the examples below (parentheses indicate ADs).
(54) a. (ko r fu)
b. (ni $k^{\text {ha' }}$ sõ)
'Golf'
c. (Po ta)(li ya)
(?o ta li ya)
'Nixon'
d. (nø sz)(la fu)
(nø sz la fu)
'Australia'
e. (ku r)(pa tço fu) (ku r pa tço fu)
'Yugoslavia'
f. (Pe se')(yu pi ya)
(Pe se' nu pi ya)
'Gorbachev'
'Ethiopia' 
(54c-f) may form either two ADs (usually in slower speech) or one $\mathrm{AD}$ (usually in faster speech). Their derivations are given below.

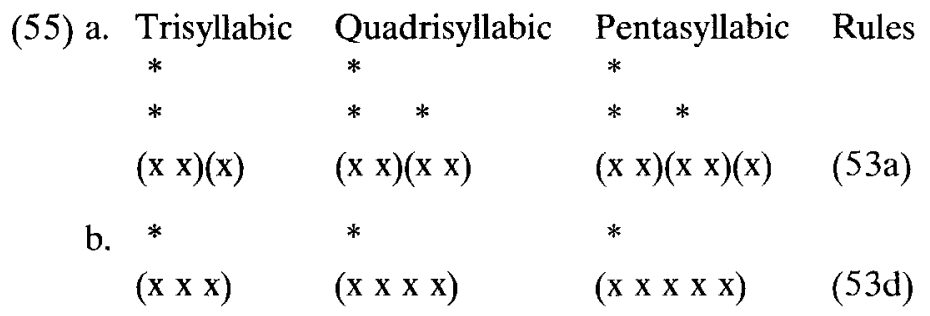

After assigning morpheme stress by (53a), we get (55a). The last syllable in the trisyllabic and pentasyllabic words is a degenerate feet and so does get stress. Thus, trisyabic words form one $A D$, as seen in $(54 a, b)$. Quadrisyllabic and pentasyllabic words form two ADs, as seen in (54c-f). If we further apply stress reduction (53d), as happens in fast speech, we get (55b), where all words form one $\mathrm{AD}$.

Let us now consider the derivation of (4a) (ignoring register, we translate [34 13 53] as [LH LH HL] respectively). I will assume that this expression is a compound. ${ }^{25}$ Thus it has left-headed stress above the morpheme level. The derivations are as follows.

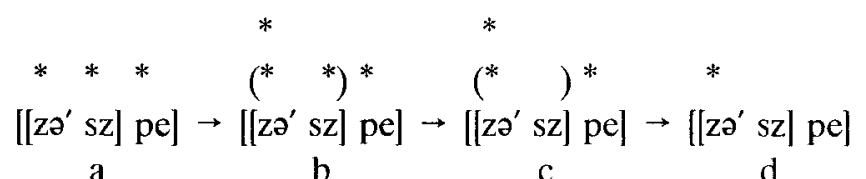

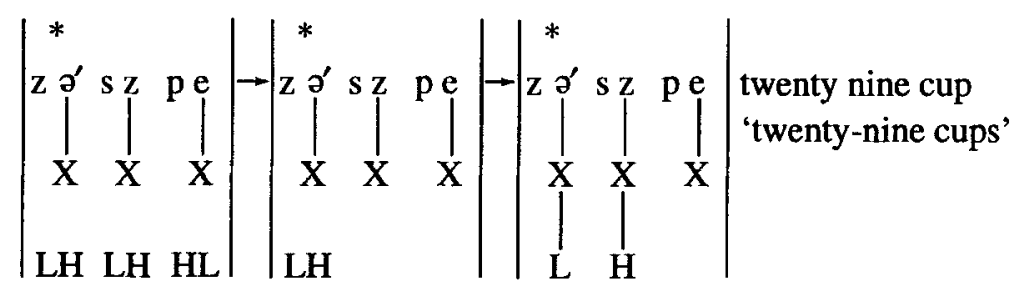

First, every morpheme is assigned a stress, as shown in (56a). Next we assign left-headed stress to $z \partial^{\prime}$ on the inner cycle, as in (56b). Since the stress on $s a^{\prime}$ clashes with that on $s z$, we delete the stress on $s z$, as in $(56 \mathrm{c})$. Finally, we apply stress reduction to delete the bottom line of stress, as in (56d) ${ }^{26}$ This leaves just one stress, on the initial syllable. (57) shows the tone rules. First, since only the initial syllable has stress, there is just one AD. Next, underlying tones on non-initial syllables are deleted, due to lack of stress. Finally, LH tones from the initial syllable link to the first two syllables one-to-one, left-to-right. Note that the first syllable is monomoraic and cannot take both tones. The last syllable either remain: toneles; 
or gets $\mathrm{L}$ as default. Other examples in (2) and (4) can be analyzed in the same way.

Let us now look at more examples. Consider (58).<smiles>[14CH4]</smiles>

When a New Shanghai syllable occurs alone, it may carry two tones. Why is this the case? One may appeal to Well-Formedness Conditions (Goldsmith (1976)), by which excess tones must link to the last syllable of an $\mathrm{AD}$. But then there is the question of why in (49), mai takes just two tones, leaving $\mathrm{H}$ unlinked. I will suggest, instead, that when an $\mathrm{AD}$ consists of just a monomoraic syllable, it can be lengthened to a bimoraic one. This proposal follows from a metrical generality variously referred to as 'the minimal word effect' (McCarthy and Prince (1990)) or the prohibition against a monomoraic foot (Prince (1992)). I state the rule in (59), along with the derivation of $(58)$ in (60).

A stressed foot must consist of at least two moras.

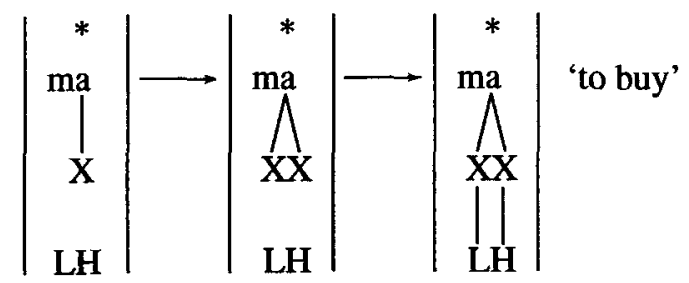

Let us now see how (59) enables us to account for more complicated examples. Consider the following.

(61)<smiles>[18OH][18OH]</smiles>

b. $\bigwedge_{\mathbf{L H}}$ 'rice'

b. ${ }^{\mathrm{t}} \mathrm{h}$

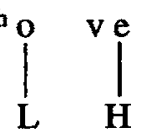<smiles>[Li][14CH3]</smiles><smiles>O=CC=CC=O</smiles>

'to fry rice'

Both $(62 a, b)$ are made of the same morphemes $(61 a, b)$, so they have the same input tones. However, $(62 a, b)$ surface with different tonal patterns. In our analysis, this is because $(62 \mathrm{a}, \mathrm{b})$ have different stress patterns. Specifically, (62a) is a compound, so the main stress falls on the first syllable. (62b) is a VP phrase, so the main stress falls on the second 
syllable. The stress assignments of $(62 a, b)$ are shown in $(63 a, b)$ respectively.

$$
\begin{aligned}
& \text { (63) a. } t^{h^{h}} \text { ve } \quad \text { b. } t^{h^{h}} \text { ve } \\
& {\left[\begin{array}{ll}
A & N
\end{array}\right] \quad\left[\begin{array}{ll}
V & N
\end{array}\right]}
\end{aligned}
$$

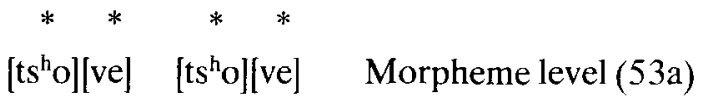

$$
\begin{aligned}
& \text { * * } \\
& {\left[\mathrm{ts}^{\mathrm{h}} \mathrm{o}\right][\mathrm{ve}] \quad\left[\mathrm{ts}^{\mathrm{h}} \mathrm{o}\right][\mathrm{ve}] \quad \text { Compound } / \text { phrase level }(53 \mathrm{~b}, \mathrm{c})} \\
& \text { * * } \\
& \text { * * } \\
& {\left[\mathrm{ts}^{\mathrm{h}} \mathrm{o}\right][\mathrm{ve}] \quad\left[\mathrm{ts}^{\mathrm{h}} \mathrm{o}\right][\mathrm{ve}] \quad \text { Clash Resolution }} \\
& \text { * * } \\
& \left(\mathrm{ts}^{\mathrm{h}} \mathrm{o}\right)(\mathrm{ve}) \quad \text { Exhaustive parsing }
\end{aligned}
$$

In (63a), each morpheme first gets a stress. Then the first morpheme gets a higher stress. Next, Clash Resolution removes the stress from the second morpheme. The result is one AD. In (63b), after Clash Resolution, the only stress left is on the second syllable, which forms an $A D$, leaving the first syllable unparsed. Here I will follow Selkirk and Shen (1990) and assume that there is a condition that requires all elements to be parsed into ADs (cf. the Exhaustive Condition of Halle and Vergnaud (1987, $15)$ ). This condition forces the first syllable in (63b) to form a foot, hence an $\mathrm{AD}$, by itself. The tonal derivations of $(63 \mathrm{a}, \mathrm{b})$ are shown in (64) and (65) respectively.

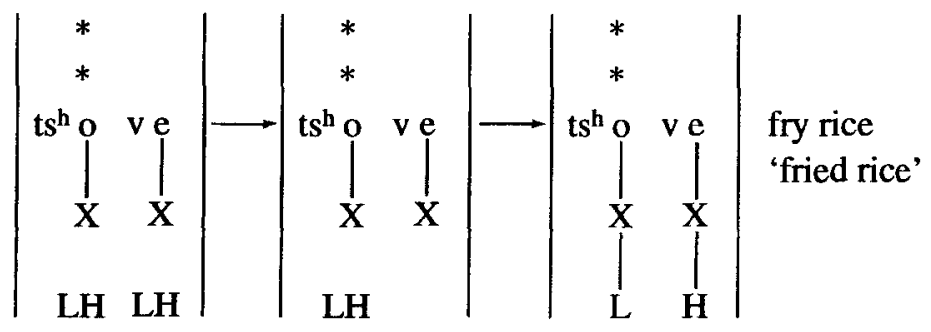


(65)

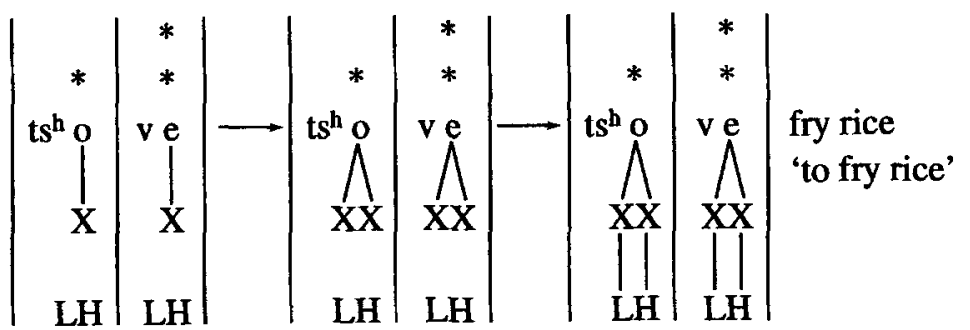

In (64), there is one AD. The $\mathrm{LH}$ of ve are deleted for lack of stress, and the LH of $t s^{h} O$ are each linked to a syllable. In (65), the two stresses create two monomoraic ADs, which by (59) become two bimoraic ADs. Both syllables retain and surface with their underlying tones. It will be noted that, in our analysis, not only will [V N] form two ADs, but the AD on $\mathrm{N}$ has greater stress. This agrees with the fact that the pitch range over $\mathrm{V}$ is narrower than that over $\mathrm{N}$, as noted by Kennedy (1953) and $\mathrm{Xu}$ et al. (1981-3) among others. ${ }^{27}$

\subsection{A Comparison}

We have seen that the rime difference between Mandarin and New Shanghai has a number of tonal consequences. The first is shown in (1)(4), namely, in Mandarin all regular syllables contribute to the phrasal tone, whereas in New Shanghai only the initial syllable contributes to the phrasal tone. The second consequence is seen in the difference between the Mandarin (52) and the New Shanghai (64), repeated below.

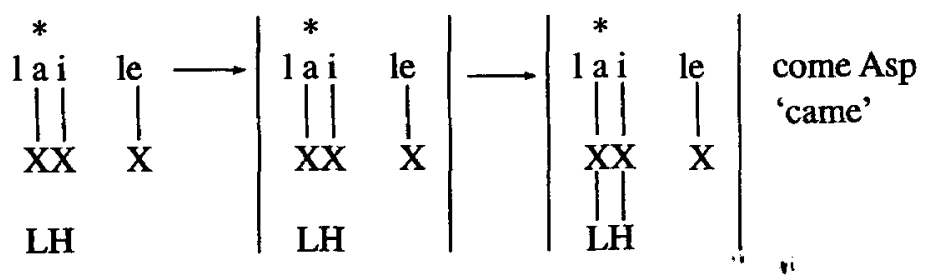

(64)

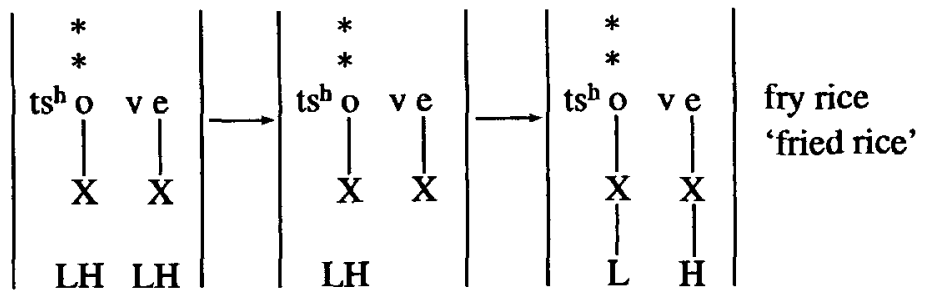

In both cases, there is one domain, with two tones to associate. In Mandarin (52) the initial syllable takes both tones, whereas in New Shanghai (64) the initial syllable takes just one. The contrast between (52) 
and (64) has, in part, lead Yip (1989), among others, to postulate that LH in Mandarin is parametrically different from LH in New Shanghai, in that in Mandarin LH is a contour tone unit, but in New Shanghai, $\mathrm{LH}$ is a cluster. In our analysis, however, there is no need to postulate the parametric difference. This is because Mandarin rimes are heavy and have two TBUs, whereas New Shanghai rimes are light and have just one TBU.

A third consequence is seen in the sensitivity of the AD to syntax. As shown in (62), in New Shanghai [A N] forms one AD, but [V N] forms two. In Mandarin, however, this is not the case. Consider the corresponding expressions in Mandarin.

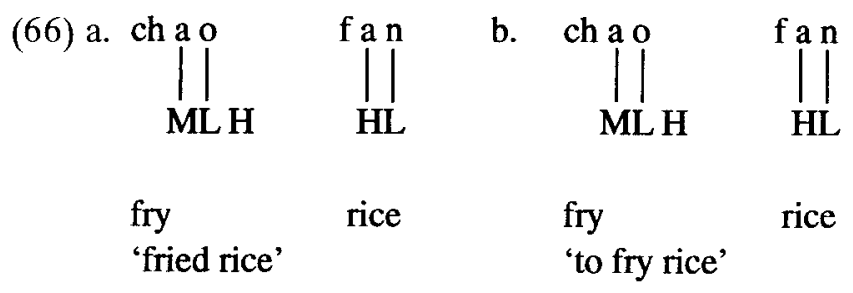

The underlying tones of chao 'to fry' are MLH, and those of fan 'rice' are HL. However, whether the two morphemes make [A N] in (66a) or $[\mathrm{V} \mathrm{N}]$ in (66b), the tonal outputs are both [ML HL]. (As discussed earlier, chao has three tones but two TBUs, so its $\mathrm{H}$ cannot be realized. In phrase final positions, chao may be lengthened by another mora, where it can carry all its MLH). Why then are Mandarin ADs insensitive to syntax? In our view, the answer again lies in rime length. Recall that I have argued that full Mandarin rimes are bimoraic. I further assume, as the null hypothesis, that the compound stress in Mandarin is left-headed and the phrasal stress in right-headed, just as in English and New Shanghai. The analysis of $(66 a, b)$ are shown in $(67 a, b)$ respectively.

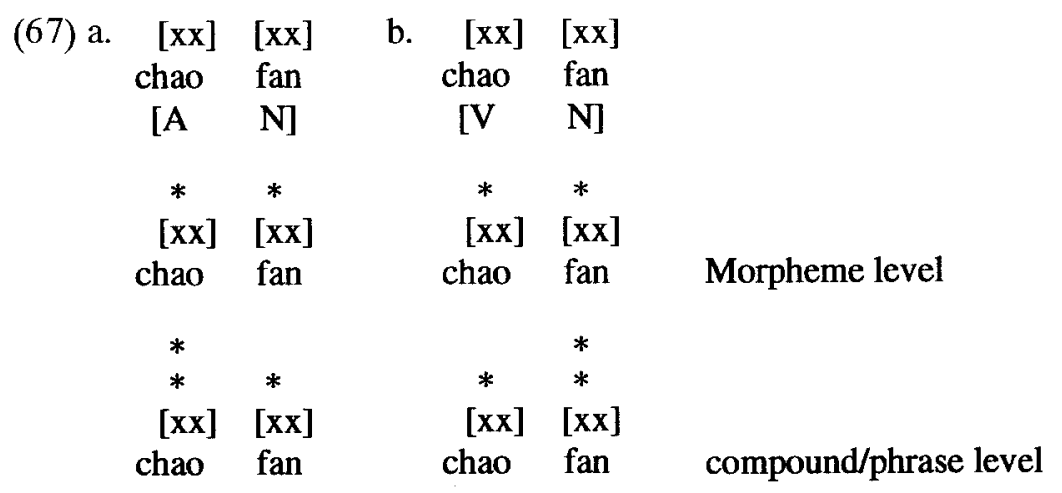

Consider (67a) first. At the morpheme level, each syllable receives a stress, which goes on to the first mora. Next, the Compound Stress Rule 
adds another stress to chao. Now, both syllables have stress. But unlike in New Shanghai, here in (67a) Clash Resolution does not apply. There are two reasons for this. First, the two stress columns are separated by a mora, so they do not constitute the most offensive clash, and thus Clash Resolution is optional (cf. Haraguchi $(1991,140)$ ). Second, if as an option Clash Resolution were to remove the stress from the second syllable, then by the Weight-to-Stress Principle, the second syllable would have to shorten, by dropping the coda for example, and become a simple rime. Now since Mandarin has a large number of complex rimes, applying Clash Resolution in cases like (67a) would cause a dramatic loss of many lexical distinctions carried by complex rimes, in addition to the loss of tonal distinctions carried by non-initial syllables. ${ }^{28}$

Next consider (67b), Unlike (67a), (67b) is a phrase, not a compound. Thus, after morpheme stress, the phrasal stress is assigned to fan. As in (67a), Clash Resolution will not apply in (67b), and both syllables will retain their stresses. Thus, both $(67 a, b)$ form two ADs and surface with the same tones, resulting in an apparent insensitivity of ADs to syntax.

Our analysis shows that despite their differences, Mandarin and New Shanghai have significant similarities. In both languages, the TBU is the moraic segment instead of the rime as a whole. Second, contour tones are made of level tones, and there is no need to postulate contour tone units. Third, each TBU takes at most one level tone. Finally, I have shown that the difference between Mandarin and New Shanghai with respect to ADs, as shown in (1)-(4), is ultimately due to their difference in syllabic structure. There is no need to assume different stress rules or domain rules for Mandarin and New Shanghai.

\section{A HISTORICAL SCENARIO}

Assuming that M-languages reflect earlier forms of Chinese rimes and that S-languages have undergone rime simplification, we ask how exactly this change took place and what stages this change went through. In addition, we want to find the intermediate stages in those dialects that are halfway through the transition. In this section I offer some tentative suggestions that bear on this issue.

I suggest that the pre-condition for a language to shift from an $\mathrm{M}$-language to an S-language is the simplification of its rime inventory, i.e., that all its rimes have become simple (cf. Section 2.3). Why the rimes of so many Chinese languages have become simple remains unclear to me and will be left open.

Once the rimes have become simple, they do not immediately become 
monomoraic. What happens at first, it seems, it that the rime will remain bimoraic whenever it has sufficient stress and start to become monomoraic when stress is weak. A dramatic example is Danyang. As I have argued, Danyang has already simplified its rimes. According to Lü (1980), Danyang has two speech styles, a colloquial style and a reading style. In the reading style, Danyang behaves like an M-language: every syllable keeps its underlying tones and starts an $\mathrm{AD}$ by itself. In the colloquial style, however, Danyang behaves like an S-language: the AD is determined by cyclic stress assignment (cf. Duanmu (1991), but see Chan (1991) for a different analysis) and may extend to several syllables, and the tonal pattern of the $\mathrm{AD}$ is determined largely by the initial syllable. In our analysis, the reading style can be regarded as adding an extra stress on every syllable (morpheme), and this extra stress (plus the morphemic stress of every syllable) is sufficient to keep a simple rime bimoraic, hence protecting its stress from Clash Resolution, and thus retaining its underlying tones and forming an $\mathrm{AD}$. As in an M-language, once every syllable is bimoraic, higher stresses no longer have obvious tonal effects. In the colloquial style, however, the morphemic stress is not sufficient to keep a simple rime bimoraic. Higher stresses will then play a visible role. In particular, Clash Resolution will remove stresses from syllables adjacent to a higher stress, and thus multisyllabic $\mathrm{ADs}$ will frequently be formed. In each $\mathrm{AD}$, the initial syllable carries not only its morphemic stress, but also higher stress(es), while nor-initial syllables have no stress. Thus, underlying tones from non-initial syllables are deleted, but those of the initial syllable are kept, which determines the pitch pattern of the AD. Moreover, the strong stress on the initial syllable will keep it bimoraic, so it will pick up two tones during tonal association. This is seen in the Danyang quadrisyllabic patterns [42 1111111$]$ and [24 5555 55], where the initial syllable carries two tones $(\mathrm{HL}=42, \mathrm{LH}=24){ }^{29} \mathrm{~A}$ similar situation is reported in Nantong, where in slow speech every full syllable starts an $\mathrm{AD}$, but in fast speech several full syllables can merge into a multisyllabic $A D$, whose pitch pattern is determined by the initial syllable (Ao (1992)).

At the next stage the tendency to shorten rimes becomes stronger. The reading style, or the slow speech style, is no longer sufficient to keep every syllable bimoraic. However, higher stresses on domain-initial syllables may still keep them bimoraic. Thus, we see such dialects as Wuxi and Suzhou, where multisyllabic domains occur in both reading and colloquial styles and where the domain-initial syllable may carry a contour tone (i.e., LH or $\mathrm{HL}$ ).

Up to this point, bimoraic syllables occur in two environments: (a) when the syllable forms an $\mathrm{AD}$ by itself, and (b) when the syllable is in the 
initial position of a multisyllabic $\mathrm{AD}$. Now, with respect to metrical principles, (a) and (b) are not equally stable. In particular, there is a metrical tendency to avoid a monomoraic foot, so the syllable in (a) will remain bimoraic. On the other hand, there is a metrical tendency to avoid a trochaic (left-headed) foot with a bimoraic initial syllable, so the initial syllable in (b) will tend to become monomoraic (cf. the Grouping Harmony of Prince (1992)). This, I suggest, is the next stage of development. An excellent example is found in Old Shanghai, spoken in some suburban areas of Shanghai City as well as by elderly people in downtown Shanghai (T. Shen (1981a, b, 1982), Xu et al. (1988)). Consider the following. ${ }^{30}$

(68) a

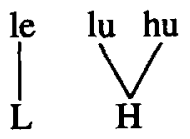

'imported goods'

b.<smiles>CCCCC(C)C</smiles><smiles>CCOCC</smiles>

The initial syllables in $(68 \mathrm{a}, \mathrm{b})$ both have underlying LH. However, the initial syllable in (68a) takes just $\mathrm{L}$, whereas that in (68b) may either take both LH, or just take L (T. Shen (1981b)). In our view, (68a, b) show that the initial syllable in Old Shanghai is undergoing shortening. It is interesting to note that the shortening process seems to take place earlier in some syllables than in another. For example, consider initial syllables with underlying LH. All those with voiceless onsets may optionally take L or LH. For those with voiced onsets, some may still take either L or LH, and others may take just $\mathrm{L}$. How exactly voicing interacts with rime shortening is not exactly clear and will be left for further studies.

Let us now look at the final stage, where the shortening of the initial rime in all multisyllabic ADs is completed. The best example is shown by New Shanghai. Compare the Old Shanghai $(68 \mathrm{a}$, b) with the New Shanghai below.

(69) a. $\prod_{\mathbf{L}}^{\text {le }} \prod_{\mathbf{H}}^{\mathrm{lu}} \mathrm{hu}$<smiles>[3H][14CH2][13CH3]</smiles>

'imported goods'

'office'

Like in $(68 \mathrm{a}, \mathrm{b})$, both initial syllables in $(69 \mathrm{a}, \mathrm{b})$ have underlying $\mathrm{LH}$. But unlike in $(68 \mathrm{a}, \mathrm{b})$, where the initial syllable may optionally take both 
LH, the initial syllable in New Shanghai can take just L. ${ }^{31}$ On the other hand, like in Old Shanghai, when a syllable forms an AD by itself in New Shanghai, it still remains bimoraic and takes up two tones, as discussed in (58)-(60).

Below I summarize the proposed stages in the evolution from an M-language to an S-language.

\begin{tabular}{|c|c|c|}
\hline RIME & PROPERTIES & LANGUAGES \\
\hline complex & $\begin{array}{l}\text { All full rimes are heavry. Every } \\
\text { full rime (plus one or more weak } \\
\text { rimes, if any) forms an Ad. }\end{array}$ & $\begin{array}{l}\text { Mandarin, Cantonese, } \\
\text { Taiwanese, ... }\end{array}$ \\
\hline simple & $\begin{array}{l}\text { Rimes remain bimoraic with } \\
\text { stress and become monomoraic } \\
\text { without stress. }\end{array}$ & Danyang, Nantong \\
\hline Simple & $\begin{array}{l}\text { Rimes may remain bimoraic with } \\
\text { strong stress. Some rimes begin to } \\
\text { shorten even under stress. }\end{array}$ & $\begin{array}{l}\text { Suzhou, Wuxi, Old } \\
\text { Shanghai, ... }\end{array}$ \\
\hline simple & $\begin{array}{l}\text { Rime remains bimoraic only in a } \\
\text { monosyllabic } A D \text {. Otherwise all } \\
\text { rimes are monomoraic. }\end{array}$ & New Shanghai \\
\hline
\end{tabular}

It is perhaps not an accident that the phonological transition from $(71 \mathrm{a}-\mathrm{d})$ coincides with both the geographical transition (e.g., BeijingDanyang-Suzhou-Shanghai) and the diachronic transition (Old Shanghai-New Shanghai). It is also amazing how fast a language changes: the shift from Old Shanghai, still spoken by elderly people, to New Shanghai, widely spoken by young people, has taken place in less than two generations.

\section{CONCLUDING REMARKS}

In the preceding sections I have offered an analysis according to which the contrast between the lack of phrasal sandhi in (1) and (3) and the presence of phrasal sandhi in (2) and (4) is connected with rime length, stress, and the domain of tonal association. I have shown that independent principles of syllable and stress can shed light, for the first time, on such widely different tonal patterns as found in Mandarin, Danyang, Suzhou, Old Shanghai, and New Shanghai. 
Admittedly, the present proposal is sketchy in places, and a number of questions remain to be answered. Let me mention two such questions.

First, our analysis predicts that a language with a simple rime inventory should move towards an S-language in terms of tone sandhi. However, Shuangfent, of the Xiang Family, appears to have a simple rime inventory (HYFYZH (1989) 23-24), yet I have seen no report on tone sandhi (or the lack of it) in this language.

Second, our analysis predicts that if a language has complex rimes, it should behave like an M-language, with no multisyllabic ADs that contain more than one full rime, since each full rime starts a new $A D$. An apparent counter-example is Changchow (of the Wu family), which has complex rimes, yet several of its bisyllabic sandhi patterns resemble those of Shanghai (Chao $(1970,46,50))$. However, those sandhi patterns occur only when the first syllable is stressed and the second is unstressed (Chao, p. 49). When the second syllable is stressed, the only change is [523] $\rightarrow$ $[52]$ and $[13] \rightarrow[11]$ on the initial syllable, which seems to be tonal simplification of the initial syllable. Thus, Changchow may not be an exception to our analysis after all.

Tone sandhi in Chinese is often studied without reference to rime length and stress. As a result, conclusions are often drawn that the TBU is the syllable or the rime as a whole and that some contour tones are structured as a unit, instead of being a sequence of level tones (Yip (1989, 1992), Bao (1990), Chen (1992), among others). If our analysis is correct, then it weakens the claim that the TBU is the syllable or the rime as a whole, nor is there necessity for positing contour tone units (cf. Duanmu (1992b) for other arguments against contour tone units). Our analysis points to a more constrained theory of tonal representation and TBU, and narrows the typological differences between tone in Asian languages and tone in other parts of the world.

\section{NOTES}

* An earlier version of this paper was presented to an audience at the Univeristy of Michigan, Ann Arbor, and I think the participants for comments. I thank Zhiming Bao, Bill Baxter, Pam Beddor, Andre Cooper, Morris Halle, Mike Hammond, Alexis ManasterRamer, Jack Martin, and Moira Yip, with whom I discussed various aspects of the paper. I would also like to thank three anonymous JEAL reviewers for their extremely careful comments, which improved this paper considerably. Finally, I would like to thank Jim Huang for his gentle editorial guidance. All remaining shortcoming are mine.

1 Mandarin is transcibed in the Pinyin system. New Shanghai is transcribed in phonetic symbols, after X et al. (1981-1983), Xu et al. (1988). Tones are transcribed in the system of Chao (1930), where 5 means the highest pitch and I the lowest. Xu et al. $(1988,8)$ mark the five New Shanghai tones as follows 


$\begin{array}{lllll}\text { T1 } & \text { T2 } & \text { T3 } & \text { T4 } & \text { T5 } \\ 53 \text { or } 51 & 34 & 23 & 55 & 12 \text { or } 23\end{array}$

The slight variations in the markings do not concern us here.

${ }^{2}$ Here the term 'phrase' is used loosely to refer to a domain larger than a syllable.

3 A 'syllable tone', or 'isolation tone', is what occurs on a syllable when it is read in isolation. Since Chinese is a monosyllabic language, the syllable tone is basically the morpheme tone.

${ }^{4}$ In M-languages, if a full syllable is followed by stressless syllables, we can also see the same sandhi as in S-languages. We will return to this point below.

${ }^{5}$ Everett and Everett (1984) and Davis (1988) suggest that in some languages, onsets may be relevant in stress rules. However, their point is irrelevant to Chinese, since all regular Chinese syllables have an onset, including the 'zero onset' (cf. Chao 1968, Duanmu 1990).

${ }^{6}$ In most studies on syllable duration, the syllables in quetion are read in a contrastive environment, e.g., an unchanging carrier sentence, so the durations are slightly longer than in normal speech. In the latter case, a heavy rime is on the order of $160 \mathrm{~ms}$.

7 In addition, Howie $(1976,216-8)$ points out that the pitch contours on the prenuclear $\mathrm{G}$ and $\mathrm{N}$ do not agree with the expected tonal shape and that only the pitch contour starting from the nuclear vowel should be counted.

8 A JEAL reviewer (R2) points out the following data in Howie (1976).

$\begin{array}{rlrll}\text { (i) a. } & {\left[\mathrm{i}^{214}\right]} & 235 \mathrm{~ms} & \text { 'use, so as to' } & \text { (p. 48) } \\ \text { b. } & {\left[\mathrm{i}^{35}\right]} & 190 \mathrm{~ms} & \text { 'doubt' } & \text { (p. 164) } \\ \text { c. } & {\left[\mathrm{you}^{214}\right]} & 415 \mathrm{~ms} & \text { 'friend' } & \text { (p. 54) } \\ \text { d. } & {\left[\text { ÿan }^{35}\right]} & 430 \mathrm{~ms} & \text { 'round' } & \text { (p. 167) }\end{array}$

(i.a, b) are about half the duration of (i.c, d). From (i), R2 suggests that $\mathrm{V}$ rimes have one $\mathrm{X}$ slot and VX rimes two slots. There are two shortcomings in this suggestion.

First, one should compare average durations of each syllable type and not individual tokens. In Howie's data, the average duration of all GVX is in the order of $300 \mathrm{~ms}$, so (i.c, d) are exceptions. In fact, (i.c, d) are the longest two tokens in Howie's entire book.

Second, (i.c) was taken from the list where Howie was measuring the "voiced part" (pp. 155-199), so the duration covers not just the rime but also the onset G. (i.d) was taken from the list where Howie was measuring "the vowel" (pp. 48-59), but again, prenuclear $\mathrm{G}$ was included, as can be seen in Howie's analysis of [wen $\left.{ }^{35}\right]$ 'literary' and [ya ${ }^{35}$ ' 'tooth' ( $p$. 85). As Howie notes, however, the initial $G$ has a duration of about $100 \mathrm{~ms}$. Thus, the rimes of (i.c, d) must be $100 \mathrm{~ms}$ shorter.

Do (i.a, b) have an initial glide too? Are [i], [u], and [ü] in fact [yi], [wu], and [ÿu]? The answer is not exactly clear. In Howie's study, the durations of [i], [u], and [ü] syllables pattern with those without an initial $\mathrm{G}$, such as [fa] and [pao] (200 ms), not with those that have an initial $\mathrm{G}$, such as [ya] and [wen] $(300 \mathrm{~ms})$. In addition, I find there to be a contrast between $\left[\mathrm{P}^{55}\right]$ 'one', $\left[\mathrm{Pu}^{55}\right]$ 'room', and $\left[\mathrm{Pu}^{51}\right]$ on the one hand, and * $\left[\mathrm{Piao}^{55}\right]$ 'waist', ${ }^{*}\left[\mathrm{rua}^{55}\right]$ 'dig', and *[rüan $\left.{ }^{5 !}\right]$ 'yard' on the other. That is, $[\mathrm{P}]$ can be added to a nuclear high vowel, but not to a prenuclear G. This intuition was shared by an audience at NACCL4. Such evidence indicates that a high nuclear vowel does not automatically spread to the onset position (probably due to the rarity of a triple geminate, if the high nuclear vowel already occupies two rime slots), at least not in the speech of Howie's subject.

From these considerations, we see that the durations of (i.a, b) (200 ms or so) belong to the rime. The regular durations of (i.c, d) syllables are $300 \mathrm{~ms}$ or so, of which $200 \mathrm{~ms}$ belong to the rime. Further data, below, confirm the fact that the durations of both $\mathrm{V}$ and VX rimes are on the order of $200 \mathrm{~ms}$ (Howie, pp. 155-199; each syllable is an average of 4 tokens). 
(ii)

$$
\begin{array}{llllll}
\text { pao } & \text { bao } & \text { fa } & \text { ge } & \text { ke } \\
202 & 242 & 201 & 223 & 206 & \text { (ms) }
\end{array}
$$

${ }^{9}$ It is worth noting that, according to $\mathrm{Ng}$ (1989), without measuring the silent duration of the [ $\mathrm{p} \mathrm{t} \mathrm{k}$ ] codas, $\mathrm{Ru}$ syllables were about $100 \mathrm{~ms}$ shorter than non-Ru syllables. If we follow Duanmu (1992d) and add $100 \mathrm{~ms}$ for the duration of the $[\mathrm{p} \mathrm{t} \mathrm{k}]$ codes, then all Cantonese syllables have comparable durations.

${ }_{10}$ Two JEAL reviewers ( $\mathrm{R} 1$ and $\mathrm{R} 3$ ) pointed out that $[\mathrm{CVC}]$ syllables need not necessarily be heavy. While light $[\mathrm{CVC}]$ is indeed reported in some languages, I am not aware of any evidence that $[\mathrm{CVG}]$ and $[\mathrm{CV}:]$ can be light. Since $\mathrm{M}$-languages contain $[\mathrm{CVC}]$ and [CV:] and since there is no weight contrast between [CVC] on the one hand and [CVG] and $[\mathrm{CV}:]$ on the other, it is the null hyopothesis that [CVC] is heavy. Besides, there is no evidence that $[\mathrm{CVC}]$ is light in $\mathrm{M}$-language.

11 There have been speculations that historically Chinese tones were related to syllable length in some way. However, such speculations do not apply to modern Chinese (Chen 1979).

12 Thanks to a JEAL reviewer ( $R 2$ ) for bring up this point.

$13 \mathrm{Xu}$ et al. (1981) writes [r] as [el]. Since this rime is a single sound, I write it as [r].

14 A JEAL reviewer $(\mathrm{R} 1)$ points out that it is usual to see [VN] $\rightarrow[\tilde{\mathrm{V}}]$, but not $[\tilde{\mathrm{V}}] \rightarrow$ [VN]. I am, however, not aware of any principled reason to exclude [V] $\rightarrow$ [VN]. For example, English speaking children learning French often pronounce a nasal vowel as a vowel followed by a nasal (Beddor, p.c.) $[\tilde{\mathrm{V}}] \rightarrow[\mathrm{VN}]$ could be understood as trying to make the coda less sonorant than the nucleus, as is the case in diphthongization (e.g., [a:] $\rightarrow$ [ai]).

15 A JEAL reviewer $(\mathrm{R} 3)$ points out that if $[\tilde{V}] \rightarrow[\mathrm{VN}]$ in final positions, we should see

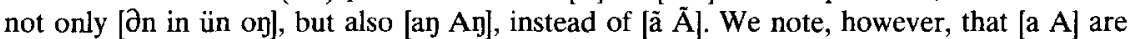
[+low], while [ $\partial \mathrm{i} \ddot{\mathrm{u}} \mathrm{o}]$ are [-low]. Thus, the fact that [ay $\mathrm{Ay}]$ do not occur in final position can be explained on independent grounds.

16 The present analysis difers slightly from that of Duanmu (1990), which assumes that all New Shanghai rimes are underlyingly bimoraic but are shortened to monomoraic in nonfinal positions.

17 The tonal patterns show that what Zee and Maddieson studied was New Shanghai, although Zee and Maddieson did not say so.

${ }_{18}$ The [V:] rime is longer for Zee and Maddieson's subject (about $300 \mathrm{~ms}$ ) than for Howie's speakers (about $200 \mathrm{~ms}$ ). This may be due to speakers' individual characteristics. We also note, though, that Howie used a different carrier frame (p. 40,147).

$$
\begin{array}{ll}
\text { zhege } \$ \text { zi, } & \text { shi } \mathrm{Lao} \mathrm{Li} \text { xie de } \\
\text { this } & \text { character is } \text { Old } \mathrm{Li} \text { write } \mathrm{Asp}
\end{array}
$$

'This character $\$$ was written by Old Li.'

Here [\$ zi] together serve as the object phrase, so $\$$ does not form an isolated domain. In fact, if this frame is used in New Shanghai, [S zi] will form one tonal domain.

${ }^{19}$ It is interesting to note that one of the Mandarin sentences contained 14 syllables, thirteen of which contained simple rimes (no diphthongs, no codas), as shown below (transcribed in Pinyin), yet the average syllable duration in this sentence for all three Mandarin speakers was still $218 \mathrm{~ms}$.

$$
\begin{aligned}
& \text { mo-shu-shi yi-xia bian-chu wu da che mo-li-hua cha } \\
& \text { magician at-once produced five big carts jasmine tea } \\
& \text { 'The magician suddenly produced five carts of jasmine tea.' }
\end{aligned}
$$

This is in agreement with Howie's findings that all full Mandarin rime types have similar durations and confirms our proposal that what was traditionally transcribed $[\mathrm{CV}]$ in Mandarin is indeed [CV:]. 
20 In Chinese, besides diphthongs, $[\mathrm{m} \mathrm{n} \mathrm{n}]$ and $[\mathrm{p} \mathrm{t} \mathrm{k}$ ?] are the only codas.

21 Ao (1992) does not discuss the rime inventory of Nantong. But as he mentioned to me (p.c.), Nantong does not have diphthongs or minimal coda contrast.

22 As Prince points out, it is not clear whether there are real cases of 'quantity insensitive' languages. We will not pursue it either.

23 Following Yip (1980), I assume 34 to be LH in the upper register, 53 to be HL in the upper register, 13 or 23 to be LH in the lower register, etc. For exposition, I will ignore register here.

24 Strictly speaking, tones are not linked to $\mathrm{X}$ slots, but to the Laryngeal branch under the Root node. For example, [a:] with LH will be represented as follows, where $\{a\}$ represents the Supra-Laryngeal features of [a] (cf. Sagey (1986), Selkirk (1988)).<smiles>[R]C([Al][Al])[Al][Tl]</smiles>

25 I follow Dai (1992) in assuming that in Chinese the nominal [A N] and [N N] are compounds, not phrases. A phrase, or a relative clause, is marked by de in $[\mathrm{X} d e \mathrm{~N}]$. This is also the assumption of Selkirk and Shen (1990).

${ }^{26}$ If Stress Reduction does not apply here, we will get two ADs ( $\left.\mathrm{x} x\right)(\mathrm{x})$, which is a good alternative pattern to (4a).

27 Two anonymous JEAL reviewers pointed out that derivations like (57) and (64) give no way of identifying the tones of the first syllable. I share their concerns and admit that the precise relation between stress and consequent syllabic changes are not yet exactly clear. Let me nevertheless offer two tentative proposals. First, consider the following analysis.

(i)

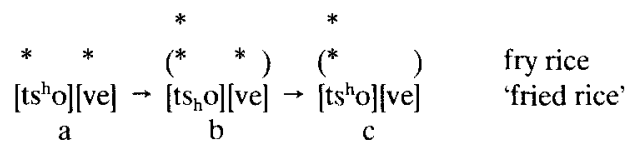

(ii)

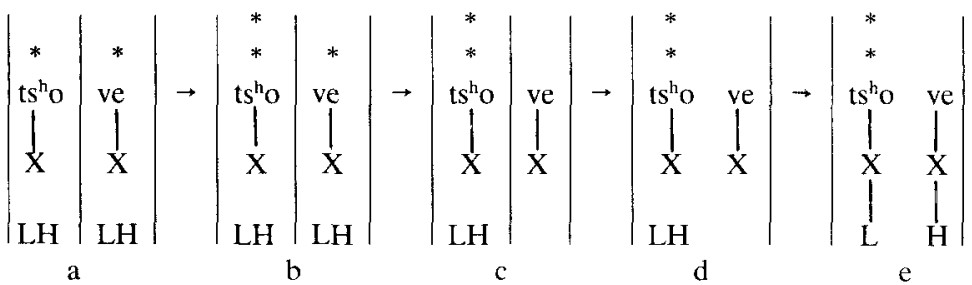

First, each morpheme is assigned stress, as in (i.a). This creates two ADs, as in (ii.a). Next, the Compound Stress Rule adds another stress to the first syllable, as in (i.b). Now Clash Resolution applies, removing the stress from the second syllable, as in (i.c). Once this happens, the second syllable loses its tones, as in (11.c). Moreover, by convention a headless (stressless) foot will lose its boundaries (cf. the Recoverability Condition and the Faithfulness Condition of Halle and Vergnaud (1987, 10-16)), so the second AD merges with the first $\mathrm{AD}$, as in (ii.d). Association rules then give (ii.e).

Now consider the second alternative. Derivations like (56)-(57) and (63)-(64) give one the impression that tonal association takes place after all stress rules. But this need not be the case. It is possible that the foot lengthening (59) and the tonal association are both cyclic. This is shown below ((i) is repeated for ease of exposition). 
(i)

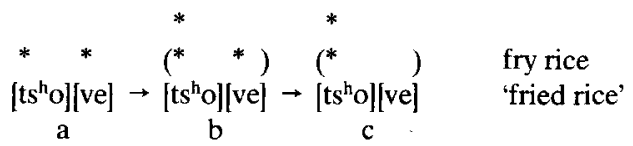

(iii)

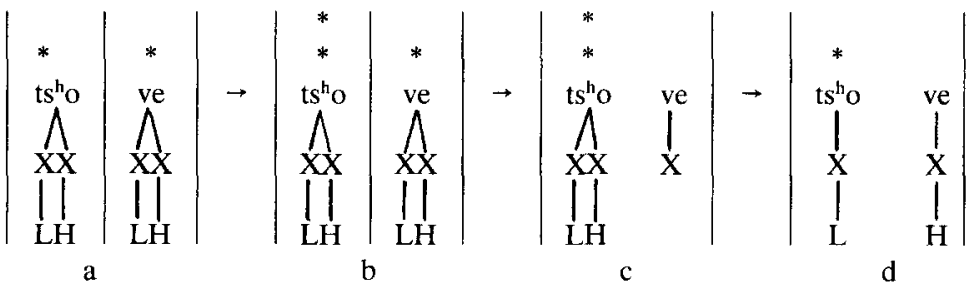

First, each morpheme is assigned stress, as in (ii.a), and each forms an AD. By (59), each syllable is lengthened to a bimoraic foot, which takes up both underlying tones, as in (iii.a). On the outer cycle, the first syllable gets another stress, as in (ii.b) and (iii.b). At this point, we have the case of $\mathrm{M}$-languages, where stresses above the morpheme level do not seem to have tonal effects. What happens next is the deletion of stress on the second syllable, either due to Stress Reduction, or due to Stress Clash (cf. Haraguchi (1991), who argues that Stress Clash is not limited to adjacent moras). Then by the Weight-to-Stress Principle, the second syllable is shortened to a light one, as in (iii.c). Apparently, only S-languages take the step from (iii.b) to (iii.c). The reason, I suggest, is that S-languages have simple rimes only, and rime shortening does not cause neutralization. If $\mathbf{M}$-languages were to take the same step from (ii.b) or (ii.c), all distinctions carried by the complex rimes would be lost, and communication would be seriously hampered.

The structure (iii.c) is exactly what we find in Old Shanghai, Danyang, and a few other Wu languages, as we will discuss in Section 5. But New Shanghai has gone a step further, shortening the initial syllable as well. This final step is justified by another metrical principle that a light-light trochee is preferred to a heavy-light one (Prince (1992)). When the initial rime shortens, a TBU is lost, and the $\mathrm{H}$ is freed and relinked to the second syllable, as in (ii.d).

For exposition, I will continue to use derivations like (56) and (57) in the rest of the paper.

${ }^{28}$ It is interesting to note that although most S-languages have lost complex rimes, most of them have kept onset voicing. In contrast, although M-languages have kept complex rimes, most of them have lost onset voicing.

${ }^{29}$ For arguments that 42 and 24 are not contour tone units, and for the analysis of [42 4242 24] in Danyang, cf. Duanmu (1992b).

${ }^{30}$ In some cases, the final syllable in an $\mathrm{AD}$ in Old Shanghai may get a $\mathrm{L}$ by an independent rule, which I will ignore.

31 Another difference we note between Old Shanghai and New Shanghai is that the $\mathrm{H}$ spreads to the right in Old Shanghai but not in New Shanghai. This I speculate, may very well be because non-initial rimes in Old Shanghai still retain traces of being heavy, so that they attract tone spreading, while those in New Shanghai are completely light, so they do not attract tone spreading. This view, if correct, implies a three-way contrast in rime weight, a point that is also raised in Prince (1992) and references cited there. 


\section{REFERENCES}

Ao, Benjamin X. P. (1992) "Metrical Constituents as Domains of Tone Sandhi in Nantong Chinese," paper presented at CLS 28, Chicago.

Bao, Zhiming (1990) On the Nature of Tone, PhD dissertation, MIT.

Bao, Zhiming (1992) "Toward a Typology of Tone Sandhi," paper presented at BLS 28, Special Session on the Typology of Tonal Systems, Berkeley.

Chan, Marjorie K. M. (1991) 'Contour-tone Spreading and Tone Sandhi in Danyang Chinese', Phonology 8.2., 237-259.

Chao, Yuen-Ren (1928) Xiandai Wuyu Yanju [Studies in the Modern Wu dialects], Tsing Hua University, Peting.

Chao, Yuen-Ren (1934/1957) "The Non-uniqueness of Phonemic Solutions of Phonetic Systems," Bulletin of Institute of History and Philology, Academia Sinica 4.4, 363-397, reprinted in M. Joos (ed.), Readings in Linguistics I, University of Chicago Press, Chicago, 1957, pp. 38-54.

Chao, Yuen-Ren (1967) "Contrastive Aspects of the Wu Dialects," Language 43.1, $92-$ 101.

Chao, Yuen-Ren (1968) A Grammar of Spoken Chinese, University of California Press, Berkeley.

Chao, Yuen-Ren (1970) "The Changchow Dialect," Journal of the American Oriental Society $90.1,45-56$.

Chen, Matthew (1979) "Metrical Structure: Evidence from Chinese Poetry," Linguistic Inquiry 10, 371-420.

Chen, Matthew (1987) "The Syntax of Xiamen Tone Sandhi," Phonology Yearbook 4, $109-149$.

Chen, Matthew (1992) "Tone Rule Typology," paper presented at BLS 28, Special Session on the Typology of Tonal Systems, Berkeley.

Clements, George N. (1986) "Compensatory Lengthening and Consonant Gemination in LuGanda," in L. Weltzels and E. Sezer (eds.), Studies in Compensatory Lengthening, Foris, Dordrecht, pp. 33-77.

Dai, John X. L. (1992) Chinese Morphology and Its Interface with the Syntax, PhD dissertation in progress, Ohio State University.

Davis, Stuart (1988) "Syllable Onsets as a Factor in Stress Rules," Phonology 5, 1-19.

Duanmu, San (1990) A Formal Study of Syllable, Tone, Stress and Domain in Chinese Languages, PhD dissertation, MIT.

Duanmu, San (1991) "Stress and Syntax-phonology Mismatches: Tonal Domains in Danyang and Shanghai," WCCFL X, Proceedings of the Tenth West Coast Conference on Formal Linguistics, ed. by Dawn Bates, Stanford Linguistic Association, pp. 127137.

Duanmu, San (1992a) "An Autosegmental Analysis of Tone in Four Tibetan Languages," to appear in Linguistics in the Tibeto-Burman Area 15.1

Duanmu, San (1992b) "Re-examining Contour Tone Units in Chinese Languages," paper presented at BLS 28, Special Session on the Typology of Tonal Systems, Berkeley.

Duanmu, San (1992c) "End-based Theory, Cyclic Stress, and Tonal Domains," paper presented at CLS 28, Parasession on the Cycle, Chicago.

Duanmu, San (1992d) "Quantifying Segmental Durations," paper presented at the Fourth North American Conference on Chinese Linguistics, Ann Arbor.

Everett, Dan and Karen Everett (1984) "On the Relevance of Syllable Onsets to Stress Placement," Linguistic Inquiry 15, 705-711.

Gleason, Henry (1955) Workbook in Discriptive Linguistics, Holt, New York.

Goldsmith, John (1976) Autosegmental Phonology, PhD dissertation, MIT.

Halle, Morris and George N. Clements (1985) Problem Book in Phonology, MIT Press, Cambridge. 
Halle, Morris and Jean-Roger Vergnaud (1980) "Three Dimensional Phonology," Journal of Linguistic Research 1, 83-105.

Halle, Morris and Jean-Roger Vergnaud (1987) An Essay on Stress, MIT Press, Cambridge.

Hammond, Michael (1984) Constraining Metrical Theory: A Modular Theory of Rhythm and Destressing, $\mathrm{PhD}$ dissertation, UCLA, Published by Garland, New York, 1988.

Goldsmith, John (1976) Autosegmental Phonology, PhD dissertation, MIT.

Halle, Morris and George N. Clements (1985) Problem Book in Phonology, MIT Press, Cambridge.

Halle, Morris and Jean-Roger Vergnaud (1980) "Three Dimensional Phonology," Journal of Linguistic Research 1, 83-105.

Halle, Morris and Jean-Rogen Vergnaud (1987) An Essay on Stress, MIT Press, Cambridge.

Hammond Michael (1984) Constraining Metrical Theory: A Modular Theory of Rhythm and Destressing, $\mathrm{PhD}$ dissertation, UCLA, Published by Garland, New York, 1988.

Haraguchi, Shosuke (1991) A Theory of Stress and Accent, Foris, Dordrecht.

Hayes, Bruce (1980) A Metrical Theory of Stress Rules, PhD dissertation MIT.

Hayes, Bruce (1992) Metrical Stress Theory: Principles and Case Studies, unpublished ms., UCLA.

Howie, John (1976) An Acoustic Study of Mandarin Tones and Vowels, Cambridge University Press, London.

HYFYZH (1989) Hanyu Fanyin Zihui [A Syllabary of Chinese Dialectal Pronunciations], 2nd edition, compiled by the Lingistics Section, Departmentof Chinese Language and Literature, Peking University, Wenzi Gaige Chubanshe, Beijing.

Hyman, Larry (1985) A Theory of Phonological Weight, Foris, Dordrecht.

Kao, Diana (1971) Structure of the Syllable in Cantonese, Mouton, The Hague.

Kennedy, G. A. (1953) "Two Tone Patterns in Tangsic," Language 29, 367-373.

Kenstowicz, Michael and Charles Kisseberth (1979) Generative Phonology, Academic Press, San Diego.

Larsen, Raymond S. and Eunice V. Pike (1949) "Huasteco Intonations and Phonemes," Language 25, 268-277.

Leben, William (1973) Suprasegmental Phonology, PhD dissertation, MIT.

Levin, Juliette (1985) A Metrical Theory of Syllabicity, PhD dissertation, MIT.

$\mathrm{Li}$, Rong (1983) "Guanyu fangyan yanjiu de ji dian yijian [Some Comments on Dialectal Studies]," Fangyan 1983.1, 1-15.

$\mathrm{Li}$, Xing-jian and Si-xun Liu (1985) "Tianjing fangyan de liandu biandiao [Tone Sandhi in the Tianjing Dialect]," Zhongguo Yuwen 1, 76-80.

Lin, Maochan and Jing-zhu Yan (1988) "The Characteristic Features of the Final Reduction in the Neutral-tone Syllable of Beijing Mandarin," Phonetic Laboratory Annual Report of Phonetic Research, Phonetic Laboratory, Institute of Linguistics, Chinese Academy of Social Sciences, Beijing, 37-51.

Lin, Maochan, Jing-zhu Yan and Guo-hua Sun (1984) "Beijing hua lian zi zu zhengchang zhong yin de chubu shiyan [Prelininary Experiments on Normal Stress in Bisyllabic Phrases in the Beijing Dialect]," Fangyan 1984.1, 57-73.

Lü, Shuxiang (1947) "Danyang hua li de lianci bian tone [Tone Sandhi in the Tan-yang Dialectl," Bulletin of Chinese Studies 7, 225-238.

Lü, Shuxiang (1980) "Danyang fangyan de shengdiao xitong [The Tonal System of the Danyang Dialect]," Fangyan 1980.2, 85-122.

McCarthy, John and Alan Prince (1990) "Foot and Word in Prosodic Morphology: the Arabic Broken Plural," Natural Language and Linguistic Theory 8.2, 209-284.

Myhill, John and Zhiqun Xing (1991) "Towards an Objective Definition of Contrast," unpublished ms., University of Michigan, Ann Arbor. 
$\mathrm{Ng}$, Kenny (1989) "A study of the Duration of Nuclear Vowels in Cantonese," unpublished ms., MIT.

Ouyang, Jue-ya (1979) "Shengdiao yu yinjie de xianghu zhiyue guanxi [The Interrelationship between Tone and the Syllable]," Zhongguo Yuwen, 359-362.

Prince, Alan (1992) "Quantitative Consequences of Rhythmic Organization," CLS 26, Papers from the 26th Regional Meeting of the Chicago Linguistic Society, Volume 2: The Parasession on the Syllable in Phonetics and Phonology, Chicago Linguistic Society, 355-398.

Pulleyblank, Douglas (1986) Tone in Lexical Phonology, Reidel Dordrecht.

Qian, Nairong and Rujie Shi (1983) "Remarks on the Tone Sandhi of Suzhou," Fangyan $83.4,275-296$.

Sagey, Elizabeth (1986) The Representation of Features and Relations in Nonlinear Phonology, PhD dissertation, MIT.

Selkirk, Elizabeth (1988) "A Two-root Theory of Length," paper presented at NELS 19.

Selkirk, Elizabeth and Tong Shen (1990) "Prosodic Domains in Shanghai Chinese," in Sharon Inkelas and Draga Zec (eds.) The Phonology-Syntax Connection, CSLI monograph, University of Chicago Press, Chicago, pp. 313-337.

Shen, Tong (1981a) "Lao pai Shanghai fang yan de lian du bian diao [Tone Sandhi in Old Shanghai]," Fangyan 1981.2, 131-144.

Shen, Tong (1981b) "Shanghai hua laopai xinpai de chabie [Differences between Old and New Shanghai Dialects]," Fangyan 1981.4, 275-283.

Shen, Tong (1982) "Lao pai Shanghai fang yan de lian du bian diao (2) [Tone Sandhi in Old Shanghai Part 2]," Fangyan 1982.2, 100-114.

Shen, Xiaonan Susan (1990) "On Mandarin Tone 4," Australian Journal of Linguistics 10 , $41-59$.

Sherard, Michael (1972) Shanghai Phonology, PhD dissertation, Cornell University.

Tsay, Jane S. (1990) "The Distribution of Tone in Taiwanese," WECOL 1989, Proceedings of the 1989 Western Conference on Linguistics, California State University, Fresno.

Tyler, Stephen A. (1969) Koya: An Outline Grammar, University of Californai Publications in Linguistics 54, Berkeley.

Wang, Futang (1959) "Shaoxing hua ji yin |A Description of Shaoxing sounds," Yuyanxue Luncong 3, 73-126.

Wang, Hongiun (1991) "Tonal System of Shaoxing Dialect," unpublished ms., MIT.

Wang, Li (1957) Hanyu Shilü Xü [Chinese Versification], Zhonghua Shujü, Shanghai.

Whalen, D. H. and Patrice Beddor (1989) "Connections between Nasality and Vowel Duration and Height: Elucidation of the Eastern Algonquian Intrusive Nasal," Language $65.3,457-486$.

Williams, Edwin (1971/1976) "Underlying Tone in Margi and Igbo," Linguistic Inquiry $7.3,436-468$.

Wright, Martha (1983) A Metrical Approach to Tone Sandhi in Chinese Dialects, $\mathrm{PhD}$ dissertation, University of Massachusetts at Amherst.

Xie, Zili (1982) "Tone Sandhi in Bisyllabic Phrases in Suzhou," Fangyan 82,4, 245-263.

Xu, Baohua, Zhenzhu Tang, and Nairong Qian (1981) "Xin pai Shanghai fangyan de lian du bian diao (1) [Tone Sandhi in New Shanghai (Part 1)]," Fangyan 1981.2, 145-155.

$\mathrm{Xu}$, Baohua, Zhenzhu Tang, and Nairong Qian (1982) "Xin pai Shanghai fang yan de lian du bian diao (2) [Tone Sandhi in New Shanghai (Part 2)]," Fangyan, 1982.2, 115--128.

$\mathrm{Xu}$, Baohua, Zhenzhu Tang, and Nairong Qian (1983) "Xin pai Shanghai fang yan de lian du bian diao (3) [Tone Sandhi in New Shanghai (Part 3),", Fangyan 1983.3, 197-201.

Xu, Baohua, Zhenzhu Tang, Rujie You, Nairong Qian, Rujie Shi, and Yaming Shen (1988) Shanghai Shiqü Fangyan Zhi [Urban Shanghai Dialects], Shanghai Jiaoyu Chubanshe [Shanghai Education Press], Shanghai.

Ye, Xiang-ling (1979) "Tone Sandhi in Suzhou," Fangyan 79.1, 30-46.

Yip, Moira (1980) Tonal Phonology of Chinese, PhD dissertation, MIT. 
Yip, Moira (1989) “Contour Tones," Phonology 6, pp. 149-174.

Yip, Moira (1992) "The Spreading of Tonal Nodes and Tonal Features in Chinese Dialects," paper presented at BLS 28 , Special Session on the Typology of Tonal Systems, Berkeley.

Yuan, Jiahua (1989) Hanyu Fangyan Gaiyao [Outline of Chinese Dialects], 2nd ed. Wenzi Gaige Chubanshe, Beijing.

Zee, Eric and Ian Maddieson (1979) "Tones and Tone Sandhi in Shanghai: Phonetic Evidence and Phonological Analysis," UCLA Working Papers in Phonetics, March, 93-129.

Zhang, Hongnian (1985) "Zhenjiang fangyan de liandu bian diao [Phrasal Tone Sandhi in the Zhenjiang Dialect]," Frangyan 1985.3, 191-204.

Zhang, H. Y. (1979) "Chongming fangyan de lian du bian diao [Tone Sandhi in Chongming]," Fangyan 1979.4, 284-302.

Zheng-zhang, Shangfang (1964) "Wenzhou yinxi [Wenzhou phonology]," Zhongguo Yuwen 1964.1, 28-60.

Zheng-zhang, Shangfang (1980) "Wenzhou fangyan er-wei ci de yuyin bianhua [Sound Changes of the er-suffix in the Wenzhou Dialect]," Fangyan 4.245-262.

Zhu, Chuan, J. J. Min, S. Y. Zhang and X. Fan (1986) Jianming Wu Fangyan Cidian [A Concise Dictionary of Wu Dialects], Shanghai Ci Shu Chubanshe, Shanghai.

Received 15 July 1991

Revised 29 May 1992

San Duanmu

Program in Linguistics

University of Michigan

Ann Arbor, MI 48109-1285

duanmu@um.cc.umich.edu 